\title{
1 African Swine Fever Virus CD2v protein promotes $\beta$-Interferon 2 expression and apoptosis in swine cells
}

3

\author{
Sabal Chaulagain ${ }^{a}$, Gustavo Delhon ${ }^{b}$, Sushil Khatiwada ${ }^{a}$, Daniel L. Rock ${ }^{\text {** }}$ \\ a. Department of Pathobiology, College of Veterinary Medicine, University of Illinois at Urbana- \\ Champaign, Urbana, IL, United States of America. \\ b. School of Veterinary Medicine and Biomedical Sciences, Nebraska Center for Virology, \\ University of Nebraska-Lincoln, NE, United States of America \\ *Address correspondence to Daniel L. Rock, dlrock@illinois.edu
}

\begin{abstract}
African swine fever (ASF) is a disease of swine characterized by massive lymphocyte depletion in lymphatic tissues due to apoptosis of B and T cells, most likely triggered by proteins or factors secreted by infected adjacent macrophages. Here we describe a role for the ASF virus (ASFV) protein CD2v in apoptosis induction in lymphocytes. CD2v is a viral homolog of host CD2 that has been implicated in viral virulence and immunomodulation in vitro; however, its actual function remains unknown. We show that $\mathrm{CD} 2 \mathrm{v}$ is secreted into culture medium of $\mathrm{CD} 2 \mathrm{v}$-expressing swine cells; and expression of- or treatment with CD2v led to significant induction of IFN- $\beta$ /ISGs transcription and antiviral state. CD2v expression led to enhanced NF$\kappa \mathrm{B}-\mathrm{p} 65$ nuclear translocation in these cultures and incubation with a NF- $\kappa \mathrm{B}$ inhibitor reduced $\mathrm{CD} 2 \mathrm{v}$-induced NF- $\mathrm{BB}-\mathrm{p} 65$ nuclear translocation and IFN- $\beta$ transcription. We show that CD2v binds CD58, the natural CD2 ligand, and that CD58 siRNA knock-down results in significant reduction in NF- $\kappa$ B-p65 nuclear translocation and IFN- $\beta$ transcription. Treatment of swine PBMC with purified $\mathrm{CD} 2 \mathrm{v}$ led to enhanced NF- $\mathrm{NB}-\mathrm{p} 65$ nuclear translocation and induction of IFN- $\beta$ transcription. Further, induction of caspase-3 and PARP1 cleavage was observed in these swine $\mathrm{PBMC}$ at later times, providing a mechanism for $\mathrm{CD} 2 \mathrm{v}$-induced apoptosis of lymphocytes. Finally, IFN- $\beta$ induction and NF- $\kappa$ B activation was inhibited in swine PBMC treated with purified CD2v pre-incubated with antibodies against CD2v. Overall, our results indicate that ASFV CD2v is an immunomodulatory protein that, by promoting lymphocyte apoptosis, may contribute to bystander lymphocyte depletion observed during ASFV infection in pigs.
\end{abstract}

IMPORTANCE ASF, a severe hemorrhagic disease of domestic swine, represents a significant economic threat to swine industry worldwide. One critical pathological event observed in pigs infected with virulent isolates is an extensive destruction of lymphoid tissue and massive lymphocyte depletion. However, viral factor/s involved in this event are yet to be identified. Here we show that, by inducing NF- $\kappa B$-dependent IFN signaling, ASFV CD2 $v$ is able to promote apoptosis in swine PBMC. We propose that $\mathrm{CD} 2 \mathrm{v}$ released by ASFV-infected macrophages contributes to the massive depletion of lymphocytes observed in lymphoid tissues of infected pigs. Results here improve our understanding of ASFV pathogenesis and will encourage novel intervention approaches. 
KEYWORDS African swine fever virus, CD2v, Interferon- $\beta$, NF- $\kappa B$, CD58, Lymphocyte, Apoptosis, Pathogenesis

\section{INTRODUCTION}

African swine fever (ASF) is a severe hemorrhagic disease of swine caused by ASF virus (ASFV), a complex enveloped DNA virus which is currently the sole member of Asfarviridae family and the only known DNA arbovirus. The disease is endemic to sub-Saharan African countries where virus cycles between bushpigs and warthogs, and Ornithodorus sp. ticks (1-4). While infection of wild pigs is asymptomatic, infection of domestic pigs can result in mortality approaching $100 \%$. Clinical forms of ASF disease range from per-acute to chronic depending on the virus strain and host factors (5-7). Lesions are most notably seen in lymphoid organs, and are characterized by massive lymphocyte depletion and lymphatic tissue destruction (6-10). Although ASF virus replicates in macrophages (11-14), infection with virulent ASFV causes marked apoptosis in B and $\mathrm{T}$ cells, which are not targets for viral replication $(3,15-19)$. It has been suggested that lymphocyte apoptosis is most likely induced by proteins or factors secreted or released by infected macrophages (19-22). Currently, no ASFV protein function has been associated with apoptosis induction in lymphocytes.

Interferons (IFNs) provide the first line of defense against virus infection. There are three different types of IFNs, types I, II and III. Type I IFNs consist of 13 IFN- $\alpha$ subtypes and IFN- $\beta$. Type II and III IFN consists of IFN- $\gamma$ and 3 subtypes of IFN- $\lambda$, respectively. Nearly all cell types produce type I IFNs when host pathogen recognition receptors (PRRs) bind different pathogen associated molecular patterns (PAMPs) (23). IFNs exert their effects by signaling through their specific receptors, leading to transcriptional induction of interferon stimulated genes (ISGs). ISGs mediate the anti-viral, anti-proliferative and immunomodulatory functions of IFN (24). Uncontrolled high levels of type I IFN during viral infection might be detrimental to the host as it has been associated with immunopathology, immunosuppression, enhanced pathology and disease progression (25). The importance of interferon for control of virus infections is reflected by the myriad of genes encoded by different types of viruses that target interferon responses $(26,27)$.

IFN- $\beta$ induction is mediated by two major groups of transcription factors, nuclear factor-kB $(\mathrm{NF}-\kappa \mathrm{B})$ and IFN-regulatory factors (IRFs) (28-32). Canonical NF- $\kappa \mathrm{B}$ activation involves inhibitor kappa- $\beta$ kinase (IKK) complex activation that leads to phosphorylation and degradation of inhibitor kappa- $\beta(\mathrm{I} \kappa \mathrm{B})$ proteins resulting in NF- $\kappa \mathrm{B}$ nuclear translocation and subsequent transcriptional induction of pro-inflammatory genes, including IFN- $\beta$ (33-38). Lack of NF- $\kappa \mathrm{B}$ activity leads to decreased expression of IFN- $\beta$ in cells $(39,40)$. Because of the central role of NF$\kappa \mathrm{B}$ in various antiviral responses, viruses target multiple steps on NF- $\kappa \mathrm{B}$ activation, from PRR recognition to $\mathrm{NF}-\kappa \mathrm{B}$ mediated gene transcription (41).

ASFV genome encodes several genes that function to interfere with NF- $\kappa \mathrm{B}$ and IFN pathways in macrophages. For example, genes of the multi-gene family 360 and 530 (MGF360/MGF530) suppress IFN induction through yet unidentified mechanisms; DP96 inhibits the cGAS-STINGTBK pathway initiated by viral DNA, leading to inhibition of NF- $\kappa$ B /IRF-3-mediated IFN- $\beta$ induction; A238L inhibits NF- $\mathrm{BB}$ activation by binding to the NF- $\kappa \mathrm{B}$ subunit RelA, and by

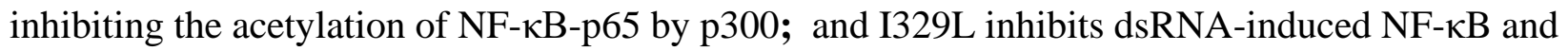
IRF3 activation (42-45). Although virulent ASFV induces very low level of IFNs inconsistently 
during infection of macrophages in vitro (46-51), pigs infected with virulent ASFV show high levels of IFNs in serum and enhanced levels of cytokines (TNF $\alpha$, IL- $1 \alpha$, IL-1 $\beta$ and IL-6) in serum and organs $(19-22,52,53)$. This suggests a role/s of IFNs of ASFV pathogenesis in pigs.

Uncharacterized soluble factors released by ASFV-infected macrophages have been shown to inhibit proliferation of swine lymphocytes in response to lectins (54). CD2v, the ASFV hemagglutinin and homolog of host $\mathrm{T}$ cell and NK cell surface antigen $\mathrm{CD} 2$, has been shown to inhibit the proliferation of lymphocytes in response to lectins, suggesting that $\operatorname{CD} 2 \mathrm{v}$ has immunosuppressive activity in vitro (55). CD2v contains all the domains present in cellular CD2 and some of the residues involved in binding to its natural ligand, CD58 $(56,57)$. CD2-CD58 interaction has been shown to activate cellular kinases in lymphocytes; however, the involvement of NF- $\mathrm{\kappa B}$ signaling downstream CD2-CD58 interaction has not been shown (58-67).

The aim of this study is to investigate immunomodulatory function/s of ASFV CD2v and define a role of $\mathrm{CD} 2 \mathrm{v}$ in induction of lymphocyte apoptosis. We show here that expression of- or treatment with- CD2v leads to induction of IFN- $\beta$, ISGs and the antiviral state in swine cells. We also show that $\mathrm{CD} 2 \mathrm{v}$ - induced IFN- $\beta$ expression requires NF- $\mathrm{KB}$ activation and CD2v-CD58 interaction. Importantly, CD2v treatment induces apoptosis in swine PBMC.

\section{RESULTS}

ASFV CD2v localizes in perinuclear region, cytoplasm and cell membrane of PK15 cells and is secreted into the culture supernatant. CD2v is an ASFV structural transmembrane glycoprotein homologous to CD2, a cell adhesion molecule expressed by T- and NK-cells $(56,57)$. $\mathrm{CD} 2 \mathrm{v}$ encodes for a protein of 370 amino acids, with a predicted molecular weight of $42 \mathrm{kDa}$ and is expressed on the surface of ASFV-infected macrophages. CD2v mediates hemadsorption of swine red blood cells (RBCs) $(56,57)$ and, together with viral C-type lectin, has a role in hemadsorption inhibition (HAI) serotype specificity (71).

To examine the subcellular localization and expression kinetics of CD2v, PK15 cells were mock transfected or transfected with pCMV plasmid expressing C-terminally HA-tagged CD2v $(\mathrm{CD} 2 \mathrm{v}-\mathrm{HA})$ and examined at various times post-transfection (pt) by confocal microscopy. CD2v was observed adjacent to the nucleus at $2 \mathrm{~h} \mathrm{pt}$, and in the cell membrane, perinuclear area and cytoplasmic vesicles at later times pt (Fig. 1A). To confirm that CD2v expressed by PK15 cells is capable of hemadsorption, PK15 cells were transfected with pEmpty-HA (control plasmid) or pCD2v-HA and incubated with swine red blood cells (RBCs) 24 h later. PK15 transfected with pCD2v-HA but not with control plasmid hemadsorbed swine RBCs as evidenced by rosette formation (Fig. 1B, arrowheads).

The expression kinetics of CD2v was assessed by Western blot after transfection of PK15 cells with CD2v-HA. Two major protein species of approximately $100 \mathrm{kDa}$ and $25 \mathrm{kDa}$, and a lessabundant $15 \mathrm{kDa}$ species were detected at $6 \mathrm{~h} \mathrm{pt}$, with increasing protein levels observed at later time points (Fig. 2A). A similar expression pattern was observed in $293 \mathrm{~T}$ cells and Vero cells (Fig. S1 in supplemental material). The observed molecular weight of the full length protein was approximately $58 \mathrm{kDa}$ higher than predicted. A single $42 \mathrm{kDa}$ band was detected when $\mathrm{CD} 2 \mathrm{v}$ was expressed in presence of tunicamycin, an inhibitor of N-linked glycosylation, confirming that the protein is heavily modified through N-linked glycosylation (Fig. S2 in supplemental material) (72). Because the $25 \mathrm{kDa}$ species is absent in presence of tunicamycin, we speculate that the $25 \mathrm{kDa}$ 
protein product might result from processing of the full length protein in the endoplasmic reticulum. A study by Goatley and Dixon (2011) has shown that CD2v in virus-infected cells is cleaved in the endoplasmic reticulum or Golgi compartments. A faint $100 \mathrm{kDa}$ and a predominant $25 \mathrm{kDa} C D 2 \mathrm{v}$ band were detected in the culture supernatant of PK15 cells $24 \mathrm{~h}$ post transfection with pCD2v-HA, indicating that $\mathrm{CD} 2 \mathrm{v}$ is secreted into the culture supernatant (Fig. 2B).

Overall, our results are in agreement with previous studies on CD2v expression in ASFVinfected cells $(56,72,73)$. In addition, this is the first study showing that CD2v is secreted into the culture medium, as previously speculated by others $(72,74)$.

\section{Expression of ASFV CD2v in PK15 cells induces IFN- $\beta$ and ISGs transcription, and the} antiviral state. Preliminary RNA-Seq experiments were conducted to examine the effect of secreted CD2v on cellular gene transcription. PK15 cells were incubated with CD2v-containing supernatant (1:2 dilution) or supernatant from cells transfected with pEmpty-HA (control plasmid), and total RNA was collected at $1 \mathrm{~h}, 2 \mathrm{~h}$ and $3 \mathrm{~h}$ post-treatment. RNA-Seq analysis showed upregulation of several interferon-stimulated genes (ISGs), including MX1,OAS1, and IRF9 at 2 $\mathrm{h}$ post treatment with further increase at $3 \mathrm{~h}$, suggesting a potential role of CD $2 \mathrm{v}$ in IFN- $\beta$ signaling (data not shown). To assess the effect of CD2v in IFN- $\beta$ and ISG transcription, PK15 cells were transfected with pCD2v-HA or control plasmids pEmpty-HA and pORFV120-Flag, the latter encoding for Orf virus protein ORFV120 and IFN- $\beta$ transcription was assessed by RT-PCR. Compared to controls, cells transfected with pCD2v-HA plasmid showed significant upregulation of IFN- $\beta$ (5.6-fold) as early as $6 \mathrm{~h}$ pt and similar upregulation was observed at all other subsequent time points (Fig. 3A). Consistent with upregulation of IFN- $\beta$, significant increase of ISGs $M X 1$ (17.7-fold) and OAS1 (12.8-fold) transcription was observed at $30 \mathrm{~h} \mathrm{pt} \mathrm{with} \mathrm{pCD2v-HA} \mathrm{plasmid}$ compared to controls (Fig. 3B and C).

To investigate the functional significance of IFN- $\beta$ and ISGs induction by CD2v, the antiviral state of cells was examined using an IFN bioassay. PK15 cells were transfected with pCD2v-HA or control plasmids (Empty-HA vector or plasmids expressing Orf virus proteins ORFV120 and ORFV113), and then infected with reporter VSV ${ }^{\mathrm{GFP}}$ (50 PFU/well) at various times pt. PK15 cells transfected with pCD2v-HA but not with control plasmids showed inhibition of VSV $\mathrm{VFP}^{\mathrm{G}}$ replication as determined by both fluorescent microscopy and flow cytometry at $12 \mathrm{~h}, 24 \mathrm{~h}$ and 30 $\mathrm{h}$ pt (Fig. 4A and B). Inhibition of $\mathrm{VSV}^{\mathrm{GFP}}$ replication was also observed after treatment of PK15 cells with a two-fold dilution of culture supernatants from cells transfected with Poly (I:C) (up to dilution 1:8) and pCD2v-HA (up to dilution 1:4) but not with control plasmids (Fig. 4C). These data indicate that expression of- or treatment with- CD2v in PK15 cells leads to induction of IFN$\beta$, ISGs and an antiviral state.

Induction of IFN- $\beta$ by ASFV CD2v depends on NF- $\kappa$ B activation. NF- $\kappa$ B and IRF3 are two important transcription factors involved in IFN- $\beta$ induction (28-32) that translocate to the nucleus upon activation. To assess whether $\mathrm{CD} 2 \mathrm{v}$ expression affects NF- $\mathrm{BB}-\mathrm{p} 65$ and IRF3 nuclear translocation, PK15 cells were transfected with pCD2v-HA or control plasmids pORFV120-Flag and pORFV113-Flag, and examined by IFA at various times pt. Enhanced NF- $\kappa$ B-p65 nuclear translocation was observed in $\mathrm{CD} 2 \mathrm{v}$ expressing cells at all times pt compared to controls (Fig. 5A and B). In contrast, IRF3 nuclear translocation was not observed (data not shown). To confirm activation of the NF- $\kappa \mathrm{B}$ pathway, PK15 cultures were transfected with pCD2v-HA or pORFV113Flag (control), and the mean fluorescence intensity (MFI) of phosphorylated NF- $\kappa \mathrm{B}(\mathrm{pNF}-\kappa \mathrm{B}$ 
S536) was examined at $3 \mathrm{~h} \mathrm{pt}$ by flow cytometry. Consistent with the nuclear translocation results, significantly increased MFI values (1.8-fold) were observed in CD2v-expressing cells compared to the control (Fig. 5C).

To assess whether inhibition of NF- $\mathrm{B}$ affects IFN- $\beta$ induction by CD2v, PK15 cells were pretreated with the NF- $\mathrm{BB}$ inhibitor parthenolide $(1 \mu \mathrm{M})$ or vehicle control (DMSO) for one hour, transfected with pCD2v-HA in presence of the inhibitor $(1 \mu \mathrm{M})$ or vehicle, and assessed for NF$\kappa \mathrm{B}-\mathrm{p} 65$ nuclear translocation at $3 \mathrm{~h}$ pt by confocal microscopy. Percentage of NF- $\mathrm{BB}-\mathrm{p} 65$ nuclear translocation in $\mathrm{CD} 2 \mathrm{v}$-expressing cells in presence of parthenolide was significantly reduced (49.3\%) compared to DMSO (Fig. 6A and B).

To investigate the effect of NF- $\kappa \mathrm{B}$ inhibition on CD2v-mediated IFN- $\beta$ induction, PK15 cells were pretreated for one hour with parthenolide $(1 \mu \mathrm{M})$ or DMSO (vehicle control), transfected with pCD2 $\mathrm{v}-\mathrm{HA}$ or pEmpty-HA (control) for $6 \mathrm{~h}$ in presence of parthenolide $(1 \mu \mathrm{M})$ or DMSO, and assessed for IFN- $\beta$ transcription by RT-PCR. Significant reduction in IFN- $\beta$ transcription was observed in cells transiently expressing $\mathrm{CD} 2 \mathrm{v}$ in presence of parthenolide (1.5-fold) compared to cells expressing CD2v in presence of vehicle alone (2.6-fold) (Fig. 6C). Together, results above indicate that induction of IFN- $\beta$ by ASFV CD2 $v$ is mediated by NF- $\kappa B$ activation.

NF- $\kappa B$ activation and IFN- $\beta$ induction by ASFV CD2 $v$ is mediated by interaction of CD2v with host CD58. CD2v contains all the domains present in cellular CD2 and some of the residues involved in binding to the CD58, the natural CD2 ligand $(56,57)$. To study the potential interaction between CD2v and CD58, PK15 cells were co-transfected with pEmpty-HA vector or pCD2v-HA and porcine pCD58-Flag, and cell lysates were prepared at $8 \mathrm{~h} \mathrm{pt}$ for reciprocal coimmunoprecipitation with anti-Flag or anti-HA antibodies as described in materials and methods. Figure 7A shows that CD2v and porcine CD58 reciprocally co-immunoprecipitate.

To confirm CD2v-CD58 interaction, PK15 cells were co-transfected with pCD2v-HA and pCD58-Flag, and co-localization of proteins was examined using confocal microscopy. Strong overlap of signals was observed (Fig. 7B). Similarly, strong reciprocal co-immunoprecipitation and co-localization of CD2v with endogenous human CD58 was observed in 293T cells transfected with pCD2v-HA, using anti-HA or anti- hu-CD58 antibodies (Fig. 8A and B). Given that: 1) CD2v interacts with CD58 (Fig. 7 and Fig. 8) and 2) host CD2-CD58 interaction activates downstream cellular kinases (58-67), we examined the involvement of CD2v-CD58 interaction in CD2vmediated NF- $\kappa \mathrm{B}$ activation and IFN- $\beta$ activation.

To evaluate the effect of CD58 downregulation on CD2v-mediated NF- $\kappa B$ activation, PK15 cells were transfected with siRNAs targeting porcine CD58 or control siRNA as described in materials and methods. CD58 transcript knock-down of approximately 55\% was routinely obtained when PK15 cells were transfected with CD58 siRNA compared to the negative control (Fig. 9A). Twenty-four hours after siRNA treatment, cells were transfected with pCD2v-HA for 3 $\mathrm{h}$, and NF- $\mathrm{BB}-\mathrm{p} 65$ nuclear translocation was assessed by confocal microscopy. Significant reduction in NF- $\mathrm{NB}-\mathrm{p} 65$ nuclear translocation $(60 \%)$ in $\mathrm{CD} 2 \mathrm{v}$ expressing cells was observed in PK15 cells with reduced CD58 transcript compared to the control (Fig. 9B, C and D).

To investigate involvement of CD58-CD2v interaction in CD2v-mediated IFN- $\beta$ induction, siRNA knock down experiments and CD2v-HA/control transfections were performed as described above. Significant reduction of IFN- $\beta$ transcription was observed $6 \mathrm{~h}$ pt with CD2v-HA in PK15 cells with reduced CD58 transcript levels (1.6-fold) compared to the control (2.3-fold) (Fig. 9E). 
Purified CD2v induces NF-кB-p65 nuclear translocation and IFN- $\beta$ transcription in swine PBMC cultures. Uncharacterized soluble factors released by ASFV-infected macrophages have been shown to inhibit proliferation of swine lymphocytes in response to lectins (54) and CD2v has been shown to be involved in inhibition of mitogen-induced proliferation of bystander lymphocytes in virus-infected swine PBMC cultures (55). This and our observations that CD2vexpressing PK15 cells secrete CD2v into the culture supernatant, and that cells treated with- or expressing CD2v upregulate IFN- $\beta$ and ISGs led us to hypothesize that 1 - secreted CD2v induces IFN- $\beta$ and ISGs expression in lymphocytes and 2- induction involves NF- $\kappa$ B-p65 nuclear translocation.

To examine NF- $\kappa$ B-p65 nuclear translocation in swine lymphocytes, swine PBMC were treated with purified CD2v or purified control for 1.5 or $2 \mathrm{~h}$, processed for IFA and deposited onto glass slides with a cytospin. Confocal microscopy analysis showed enhanced NF- $\mathrm{B}$-p65 nuclear translocation in swine PBMC treated with purified CD2v (2.8-fold at $1.5 \mathrm{~h} ; 1.6$-fold at $2 \mathrm{~h}$ ) compared to control treatment (Fig. 10A and B).

To investigate whether IFN- $\beta$ transcription in lymphocytes is affected by CD2v, swine PBMCs were treated as above and assessed for IFN- $\beta$ transcription by RT-PCR at various times posttreatment. We found that IFN- $\beta$ transcription was significantly induced in CD2v-treated PBMCs at $4 \mathrm{~h}$ (3.3-fold) and $6 \mathrm{~h}$ (3.2-fold) post treatment compared to purified control (Fig. 10C).

Supernatants from CD2v- treated swine PBMCs exhibit antiviral activity. To examine the functional significance of $C D 2 v$-induced IFN- $\beta$ expression in swine lymphocytes, swine PBMCs were treated with purified CD2v or purified control for $24 \mathrm{~h}$, and the supernatants collected, diluted, and used to treat fresh PK15 cells. Twenty-four hours after treatment the cells were infected with VSV GFP and examined for virus replication at $16 \mathrm{~h}$ post infection by IFA. Supernatant collected from PK15 cell culture transfected with Poly I:C was used as positive control. Significant inhibition of $\mathrm{VSV}^{\mathrm{GFP}}$ replication was observed in PK15 cells treated with supernatant from PBMCs. We observed $32.1 \%$ inhibition with undiluted supernatant, $24.4 \%$ inhibition with 1:2 dilution and $28.1 \%$ inhibition with 1:4 dilution (Fig. 11A and B).

CD2v induces apoptosis in swine PBMCs. ASF is characterized by severe destruction of lymphoid tissue and massive lymphocyte depletion due to apoptosis $(3,7,8,16,19,20)$. An explanation for this critical pathogenic event is lacking. ASFV replicates in cells of the monocyte lineage, most notably macrophages, but not in lymphocytes, thus apoptosis in bystander lymphocytes is most likely due to proteins or factors secreted by infected macrophages. Based on our data, we hypothesize that CD2v released by infected macrophages induces IFN expression in bystander lymphocytes leading to apoptosis.

To investigate the effect of CD2v on PBMC apoptosis, swine PBMC cultures were treated with purified CD2v, purified control, or staurosporine (positive control) as described in the materials and methods, and caspase-3 activation and PARP1 cleavage assessed by Western blot at various times post treatment. As shown in Fig. 12 A-C, treatment of swine PBMCs with purified CD2v led to significant induction of caspase- 3 activation at $18 \mathrm{~h}$ post treatment (1.9-fold) and PARP1 cleavage at $18 \mathrm{~h}$ (1.9-fold) and $24 \mathrm{~h}$ (1.6-fold) post treatment compared to purified control. This result indicates that $\mathrm{CD} 2 \mathrm{v}$ treatment induces apoptosis in swine PBMC.

Treatment with monoclonal antibodies against ASFV CD2v inhibits CD2v- induced NF$\kappa B$ activation and IFN- $\beta$ transcription in swine PBMCs. Monoclonal antibodies against ASFV 
$\mathrm{CD} 2 \mathrm{v}$ were generated and screened as described in materials and methods. Four anti-CD2v antibodies (A4, C4, C3 and F2) were used as a mixture to examine their reactivity against CD2v. The antibodies mix detected the full length $100 \mathrm{kDa}$ CD2v species in Western blot (Fig. 13A). To confirm reactivity of antibodies, lysates from 293T cells transfected with pCD2v-HA were incubated overnight with the anti-CD2v monoclonal antibodies. Immunoprecipitation products were assessed by Western blot using anti-HA antibodies. Strong pull down of CD2v by anti-CD2v monoclonal antibodies was observed in CD2v- but not in control-transfected cells (Fig. 13B). The results show that the anti-CD2v monoclonal antibodies react with $\mathrm{CD} 2 \mathrm{v}$.

To investigate the effect of the anti-CD2 $v$ antibodies on $C D 2 v$-induced NF- $\kappa B$ activation in swine PBMC, purified CD2v or purified control were incubated overnight with the monoclonal antibody mix, anti-ORFV086 monoclonal antibody, or anti-IgG mouse isotype antibody control. Swine PBMCs were then treated with purified CD2v or purified control pre-incubated with the various antibodies, processed with NF- $\mathrm{KB}$ nuclear translocation assay as above, and analyzed by confocal microscopy. As a control for the experiment, purified CD2v or purified control without pre-incubation with antibodies was used to treat swine PBMCs. Significant inhibition of NF-кBp65 nuclear translocation (approximately 50\% reduction) was observed in PBMCs treated with $\mathrm{CD} 2 \mathrm{v}$ previously incubated with anti-CD2v monoclonal antibodies compared to controls (Fig. 14A and $\mathrm{B}$ ). This result supports a role of secreted CD2v in induction of NF- $\mathrm{kB}-\mathrm{p} 65$ nuclear translocation in swine PBMCs.

The effect of the anti-CD2v monoclonal antibodies on CD2v-induced IFN- $\beta$ expression in swine PBMC, was investigated by pre-incubating purified $C D 2 \mathrm{v}$ or purified control with the monoclonal antibodies as above, followed by treatment of PBMC. As a control for the experiment, purified CD2v or purified control without pre-incubation with antibodies was used to treat swine PBMC. Total RNA was extracted $6 \mathrm{~h}$ post treatment and IFN- $\beta$ transcription was assessed by RTPCR. Significant inhibition in IFN- $\beta$ transcription was observed when swine PBMCs were treated with purified $C D 2 v$ pre-incubated with anti-CD2v antibody mix (1-fold) as compared to purified $\mathrm{CD} 2 \mathrm{v}$ pre-incubated with anti-ORFV086 monoclonal antibody (1.5-fold) or without preincubation (1.8-fold). These results confirm a role of CD2v in the induction of IFN- $\beta$ transcription in swine PBMCs (Fig. 15).

\section{DISCUSSION}

A landmark of acute ASF is the severe lymphoid tissue destruction and massive lymphocyte depletion in infected pigs, which occurs as a result of bystander lymphocyte apoptosis $(3,8,19)$. Since lymphocytes do not support ASFV replication, factors secreted by infected macrophages have been implicated in triggering lymphocyte apoptosis $(16,19-22)$. ASFV CD2v is a glycoprotein with homology to host CD2, an adhesion molecule expressed by T and NK cells (56, $57,72)$. CD2v has been shown to be involved in host immunomodulation, virulence and induction of protective immune responses $(55,75,88)$. Here, we show that expression of ASFV CD2v in swine cells induces NF- $\kappa$ B-mediated IFN expression through interaction with CD58 (Fig. 3, Fig. 5 and Fig. 9). We observed that treatment of swine PBMC with purified CD2v leads to significant IFN- $\beta$ induction, NF- $\kappa$ B-p65 nuclear translocation (Fig. 10A and B), and caspase-3 and PARP1 cleavage, thus providing a mechanism for CD2v-induced lymphocyte apoptosis (Fig. 12). 
The relationship between ASFV infection and the IFN system is complex. ASFV has evolved multiple strategies to counteract activation of the IFN and NF- $\kappa$ B signaling pathways (42-45). In vitro infection of porcine macrophages with low virulence ASFV strains induced enhanced and sustained IFN induction compared to virulent strains (46-51). However, acute ASFV infection of pigs is characterized by high level of systemic IFN production $(52,53)$. Viral factors involved in IFN induction and sources of IFN during acute ASF infection remain to be identified. Here, we describe an immunomodulatory function of ASFV CD2v that, by targeting lymphocytes for apoptosis, may contribute to the massive lymphocyte depletion observed in vivo.

CD58/LFA-3 is the natural ligand for host CD2 protein, and CD2-CD58 interaction initiates cellular kinase signaling (58-67). We show that swine CD58 interacts with CD2v, and that the interaction is involved in $\mathrm{CD} 2 \mathrm{v}$-mediated IFN- $\beta$ induction through NF- $\kappa \mathrm{B}-\mathrm{p} 65$ nuclear translocation (Fig. 7 to 9). Since viral glycoproteins can also induce IFN- $\beta$ through TLR-4/TLR-2 (76-79), involvement of these receptors cannot be ruled out. It will be interesting to determine whether the CD2v cytoplasmic domain, known to interact with the trans-Golgi network AP-1 factor and actin-binding adaptor protein $\mathrm{SH} 3 \mathrm{P} 7(73,80)$, plays a role in CD2v immunomodulation.

In ASFV-infected macrophages, CD2v is processed and thought to be secreted (72-74). Here, we show for the first time that $\mathrm{CD} 2 \mathrm{v}$ is released into the supernatant by CD2v-expressing cells (Fig. 2B). Previous studies have described the involvement of soluble factor/s in the inhibition of lymphocyte proliferation in PBMCs infected with ASFV or incubated with cell extracts/supernatants free of virus $(54,55)$ and have defined an immunomodulatory role of CD2v in inhibition of mitogen-induced proliferation of bystander lymphocytes (55). Based on our findings, secreted CD2v could be mimicking host CD2 by interacting with CD58, thus leading to induction of IFN- $\beta$ and inhibition of lymphocyte proliferation. Our observation that anti-CD2v monoclonal antibodies inhibit CD2v-dependent NF- $\kappa$ B-p65 nuclear translocation and IFN- $\beta$ induction further strengthen the immunomodulatory role of secreted CD2v (Fig. 14).

The role of CD2v in ASFV virulence is not clearly understood. Infection of pigs with a CD2v deletion mutant virus resulted in different infection phenotypes depending on the parental virus strain. CD2v deletion in the Spanish strain BA71 resulted in virus attenuation (75), and the CD2v gene has been found interrupted in some attenuated ASFV strains (82) suggesting a role of CD2v in virus virulence. In contrast, deletion of $C D 2 v$ in virulent strains Malawi and Georgia 2007 did not significantly affect virus virulence in pigs $(55,81)$. Although not essential for viral replication in pigs, $C D 2 v$ is critical for virus replication in the tick $(83,84)$. Results here support a role of ASFV CD2v in viral pathogenesis and virulence by affecting lymphocyte survival.

$\mathrm{CD} 2 \mathrm{v}$ protein has been implicated in protective immunity. CD2v expression is required for partial protection conferred by specific vaccine constructs, and two predicted CD2v T-cell epitopes are speculated to affect protective immunity (85-87). Using ASFV inter-serotypic chimeric viruses and vaccination/challenge experiments in pigs, serotype-specific CD2v and/or C-type lectin proteins were shown to be important for protection against homologous ASFV infection (88). Others, however, have found that inoculation of pigs with the BA71 virus lacking CD2v conferred protection against parental BA71 (75). This variability likely reflects the differences in the virulence of the challenge strains used in the experiments. In conclusion, CD2v represents an important factor contributing to lymphocyte depletion observed during ASFV infection in animals (Fig. 16). 


\section{MATERIALS AND METHODS}

Cells. Porcine kidney cells (PK15) and monkey kidney cells (Vero) were obtained from American Type Culture Collection (ATCC) and were maintained at $37^{\circ} \mathrm{C}$ with $5 \% \mathrm{CO} 2$ in minimal essential medium (MEM) supplemented with $10 \%$ fetal bovine serum (FBS) (Atlanta Biologicals, Flowery Branch, GA), 2mM L-glutamine, gentamicin $(50 \mu \mathrm{g} / \mathrm{ml})$, penicillin $(100 \mathrm{IU} / \mathrm{ml})$, and streptomycin $(100 \mu \mathrm{g} / \mathrm{ml})$. Human embryonic kidney (HEK 293T) were cultured in Dulbecco's modified essential medium (DMEM) supplemented as above.

Plasmids and transfection. ASFV Congo strain CD2v was synthesized, cloned into pUC57 (Genscript, Piscataway, NJ) and amplified with primers CD2v-Fw (EcoRI) (5'TAAGGCCTCTGAATTCGCCACCATGATAATTAACTTATTTTTTTAATATG-3') and CD2v-Rv (KpnI) (5'-CAGAATTCGCGGTACCAATAATTCTATCT ACATGAATAAGCG-3'). The amplified full length $C D 2 v$ gene was cloned into EcoRI and $K p n I$ sites of pCMV-HA vector (Clontech, Mountain View, CA) to produce pCD2v-HA, which express C-terminally HA-tagged $\mathrm{CD} 2 \mathrm{v}$ protein (CD2v-HA). To enhance translation efficiency, a Kozak sequence (GCCACC) was placed in front of the $C D 2 v$ gene. The construct was sequenced to confirm integrity and fidelity.

To construct expression plasmids pORFV120-Flag and pORFV113-Flag, ORFV120 and ORFV113 coding sequences were PCR-amplified from orf virus strain OV-IA82 genome and cloned into p3xFlag-CMV-10 vector (pFlag) (Clontech).

For transfection of cells, Lipofectamine 2000 (Invitrogen) and plasmid DNA were separately diluted in Opti-MEM medium (Gibco) and incubated for $5 \mathrm{~min}$. Diluted DNA was added to diluted lipofectamine 2000 (1:1ratio) and incubated for $20 \mathrm{~min}$. Finally, DNA-lipid complex was added to cells and $5 \mathrm{~h}$ after incubation, Opti-MEM medium was replaced with $10 \%$ complete growth media.

Hemadsorption assay. PK15 cells grown in 6-well plates were mock transfected or transfected with plasmid (p) CD2v-HA. At $24 \mathrm{~h}$ post-transfection (pt), culture media was removed and rinsed two times with PBS. Transfected cultures were incubated with PBS-washed $1 \%$ swine RBC overnight and observed with microscope (X100).

Swine PBMCs isolation, freezing and culture. Swine PBMCs were obtained from swine whole blood through density gradient centrifugation using Sepmate15 (Stem cell technologies) and lymphocyte separation media (Corning), and frozen in freezing media (50\% RPMI-1640, 40\% FBS, $10 \%$ DMSO) as described elsewhere $(68,69)$. Swine PBMC were maintained at $37^{\circ} \mathrm{C}$ with $5 \%$ CO2 in RPMI 1640 medium (Corning) supplemented with 10\% fetal bovine serum (FBS) (Atlanta Biologicals, Flowery Branch, GA), 2mM L-glutamine, gentamicin $(50 \mu \mathrm{g} / \mathrm{ml})$, penicillin (100 IU/ml), streptomycin $(100 \mu \mathrm{g} / \mathrm{ml})$ and sodium pyruvate $(1 \mathrm{mM})$.

CD2v purification. For CD2v protein purification, 293T cells were transfected with pCD2vHA or pEmpty-HA control vector for $30 \mathrm{~h}$. Cell lysates were harvested using mammalian protein extraction reagent (MPER) (Thermo Scientific) and incubated with anti-HA resin overnight using spin columns (Thermo Scientific). Next day, CD2v was eluted using HA peptide (1 mg/ml) (Thermo Scientific) in TBS buffer (Corning). Whole cell lysates obtained from two 6-well plates were incubated with $100 \mu \mathrm{l}$ of anti-HA resin, eluted in $200 \mu \mathrm{l}$ buffer and used for downstream process. 
Monoclonal antibodies against CD2v. PK15 cells were transfected with pCD2v-HA, and whole cell lysates obtained $30 \mathrm{~h}$ pt. Lysates were incubated overnight with anti-HA antibody (Cell Signaling Technology) at $4^{\circ} \mathrm{C}$, and immunoprecipitated using $50 \mu \mathrm{l}$ of protein $\mathrm{G}$ agarose bead slurry (Millipore). Monoclonal antibodies recognizing CD2v-HA were generated by immunizing BALB/c mice with immunoprecipitated CD2v-HA (100 $\mu \mathrm{g} /$ dose). To generate hybridomas, splenocytes from immunized mice were harvested and processed according to the company's protocol (STEMCELL technologies/ClonalCell-HY Hybridoma Cloning Kit). Clones were screened for reactivity against CD2v-HA by IFA using CD2v-HA-transfected PK15 cultures. Monoclonal antibody titers were estimated by IFA using goat anti-mouse Alexa fluor 488 or 594 as secondary antibody. Mice were maintained at the University of Nebraska-Lincoln (UNL) in accordance with the guidelines of UNL Institutional Animal Care and Use Committee (IACUC) and used in accordance with the guidelines of the committees.

Western Blot. Fifty $\mu \mathrm{g}$ of whole protein cell extracts or $50 \mu \mathrm{l}$ of cleared culture supernatant were resolved by SDS-PAGE, blotted to nitrocellulose or PVDF membranes and probed with primary antibody against HA (Cell Signaling Technology), caspase-3 (9662S; Cell Signaling Technology), PARP1 (sc-53643; Santa Cruz) or glyceraldehyde-3-phosphate dehydrogenase (GAPDH) (sc-25778; Santa Cruz). The blots were developed with appropriate HRP-conjugated secondary antibodies and chemiluminescent reagents (Thermo Scientific), and imaged with FluorChem R (Protein Simple). Densitometric analysis was performed using ImageJ software and all readings were normalized to GAPDH values.

Immunoprecipitation. 293T cells were transfected with pCD2v-HA, and whole cell lysates in MPER lysis buffer (Thermo Scientific) were obtained at $30 \mathrm{~h} \mathrm{pt}$ and incubated overnight with the anti-CD2v monoclonal antibody mix or anti-HA antibody (3724; Cell Signaling Technology). Pull down products were obtained by eluting in Laemmli buffer (Bio-Rad) and analyzed by Western blot using anti-HA antibody (2367; Cell Signaling Technology).

CD58 siRNA knock-down. To investigate involvement of CD58-CD2v interaction in CD2vmediated IFN- $\beta$ induction, siRNA knock down experiments were performed using CD58 sense (S) (CUUCCAGAGCCAGAACUAU) and anti-sense (AS) (AUAGUUCUGGCUCUG GAAG) siRNA duplex (Sigma Aldrich). PK15 cultures were transfected with CD58 siRNA (15 nM) and mission siRNA transfection reagent (Sigma) following the manufacturer's protocol, and transfected $24 \mathrm{~h}$ later with pCD2v-HA or control pEmpty-HA for $6 \mathrm{~h}$. CD58 knock-down was assessed by comparing transcript levels between cultures transfected with one MISSION siRNA Universal Negative control (Sigma aldrich) and CD58 siRNA-transfected cultures using RT-PCR. SYBR primers for swine CD58 were sCD58 FW 5'-ACTTAAACACTGGGTCGGGC-3' and sCD58 RV 5'-AAGCTGCAAGGATCAGGCAT-3'.

Real-time PCR. Interferon- $\beta$ (IFN- $\beta$ ) and interferon stimulated genes (ISGs) transcription were assessed in PK15 cells transfected with pCD2v-HA or control plasmids, and in swine PBMCs treated with purified $\mathrm{CD} 2 \mathrm{v}$ or purified control. Total RNA was harvested at various times post transfection/treatment with RNA-extraction kit (Zymo) and reverse transcribed with MLV-RT (Invitrogen) as previously described (70). IFN- $\beta$ and ISGs mRNAs were quantified using ABI and QuantStudio-3 Real time PCR system (Applied Biosystems, Foster city , CA), Power SYBR Green and sIFN $\beta$ Rv (5'-GCTCATGGAAAGAGCTGTGGT-3') for IFN- $\beta$ mRNA, and sMX1Fw (5'- 
and

SOAS1Rv

$\left(5^{\prime}-\right.$ TGCTTGACAAGGCGGATGA-3') for ISGs $M X 1$ and $O A S$. Fold change was calculated by comparison to Empty-HA for each time points. Experiments were conducted with biological triplicates and at least three technical replicates.

NF-кB nuclear translocation assay. Involvement of NF- $\kappa \mathrm{B}$ in $\mathrm{CD} 2 \mathrm{v}$-mediated upregulation of IFN- $\beta$ transcription was assessed by nuclear translocation assays in 1- PK15 cells transfected with pCD2v-HA or control plasmids pORFV120-Flag and pORFV113-Flag, and 2- swine PBMCs treated with purified $\mathrm{CD} 2 \mathrm{v}$ or purified control. Cells were fixed at various times post-transfection or -treatment, fixed with $2 \%-4 \%$ paraformaldehyde (PFA) (15 min), and permeabilized with $0.2 \%$ triton X100 (10 min). PK15 cells were incubated overnight at $4^{\circ} \mathrm{C}$ with primary antibody against HA (2367S; Cell Signaling Technology), control Flag (A00187; Genscript) and total NF-אB (8242; Cell Signaling Technology), and PBMCs with antibody against total NF- $\kappa$ B. PK15 cells were washed with PBS and incubated with secondary antibodies, goat anti-mouse Alexa fluor 488 (A11029; Thermo Scientific) to detect CD2v, ORFV120 and ORFV113, and goat anti-rabbit Alexa fluor 594 (A11012; Thermo Scientific) to detect total NF-кB; for PBMCs, goat anti-mouse Alexa fluor 488. PBMCs were deposited on slides using Shandon cytospin 2 centrifuge (1500 rpm, 1 min). Nuclei were counterstained with DAPI. Images were obtained with a A1 Nikon confocal microscope, and the number of cells exhibiting nuclear NF- $\kappa \mathrm{B}$ staining was determined in randomly selected fields and results were expressed as mean percentage of cells with nuclear NF$\kappa \mathrm{B}$ over three independent experiments.

To assess whether inhibition of NF- $\mathrm{B}$ affects IFN- $\beta$ induction by CD2v, PK15 cells were pretreated with the $\mathrm{NF}-\kappa \mathrm{B}$ inhibitor parthenolide (InvivoGen) at $1 \mu \mathrm{M}$ final concentration or vehicle control (DMSO) for one hour and transfected with pCD2v-HA in presence or absence of parthenolide $(1 \mu \mathrm{M})$. At $3 \mathrm{~h} \mathrm{pt}$, cultures were fixed, permeabilized, and incubated with primary antibodies against $\mathrm{HA}$ and total $\mathrm{NF}-\mathrm{\kappa B}$ as above, washed, and incubated with secondary antibodies, goat anti-mouse Alexa fluor 488 for CD2v and goat anti-rabbit Alexa fluor 594 for total NF- $\kappa \mathrm{B}$. Cells were counterstained with DAPI and percentage NF- $\kappa \mathrm{B}$ nuclear translocation in $\mathrm{CD} 2 \mathrm{v}$ expressing cells in presence or absence of inhibitor were compared over three independent experiments.

The role of CD2v-CD58 interaction in induction of NF- $\mathrm{BB}$ nuclear translocation was examined by transfecting PK15 cells with CD58 siRNA or siRNA universal negative control for $24 \mathrm{~h}$, and with pCD2v-HA $24 \mathrm{~h}$ later for $3 \mathrm{~h}$. Cultures were fixed, permeabilized and processed for HA and total NF- $\kappa \mathrm{B}$ staining as described above. Percentage of NF- $\kappa \mathrm{B}$ nuclear translocation in CD2vexpressing cells in which CD58 was knocked down were determined and compared in three independent experiments.

To investigate the effect of anti-CD2 $\mathrm{v}$ monoclonal antibody mix in CD2v-induced $\mathrm{NF}-\kappa \mathrm{B}$ activation in swine PBMCs, purified CD2v or purified control were incubated overnight at $4^{\circ} \mathrm{C}$ with anti-CD2v monoclonal antibodies or anti-ORFV086 antibody or anti-IgG mouse isotype antibody control. PBMCs grown in 96-well plates were treated with pre-incubated CD2v or nonpreincubated $\mathrm{CD} 2 \mathrm{v}$ control, processed as above for $\mathrm{NF}-\kappa \mathrm{B}$ nuclear translocation $1.5 \mathrm{~h}$ post treatment, cytospinned, and examined under the confocal microscope. Fields were randomly 
selected and scored for mean percentage of cells containing nuclear NF- $\mathrm{B}$ over three independent experiments.

Interferon Bioassay. To investigate the functional significance of CD2v-induced IFN- $\beta$ and ISGs expression, the antiviral state of cells was examined using an IFN bioassay. PK15 cells were transfected with pCD2v-HA or control plasmids pEmpty-HA or pORFV120-Flag, infected at 12 $\mathrm{h}, 24 \mathrm{~h}$ and $30 \mathrm{~h}$ pt with reporter vesicular stomatitis virus expressing GFP (VSV GFP; 50 PFU/well), fixed with $4 \%$ PFA at $16 \mathrm{~h}$ post infection, and examined by IFA in a Leica DMI 4000B.

Supernatant obtained from PK15 cultures transfected with pCD2v-HA or control plasmids pEmpty-HA or pORFV120-Flag or Poly I:C (+ control) were serially diluted and used to treat PK15 cells. At $30 \mathrm{~h}$ post-treatment, cultures were infected with $\mathrm{VSV}^{\mathrm{GFP}}$ (50 PFU/well), and virus replication was assessed $16 \mathrm{~h}$ post-infection.

The antiviral state was assessed in swine lymphocytes as follows. Supernatants from swine PBMCs treated with purified CD2v or purified control for $24 \mathrm{~h}$ or supernatant obtained PK15 culture transfected with Poly I:C (+ control) were serially diluted and used to treat fresh PK15 cells. PK15 cells were infected with $\mathrm{VSV}^{\mathrm{GFP}}$ (50 PFU/well) $24 \mathrm{~h}$ post treatment, and virus replication was examined $16 \mathrm{~h}$ post infection as described.

Flow cytometry. PK15 cells were transfected with pCD2v-HA or control plasmids, and then infected with VSV GFP at $12 \mathrm{~h}, 24 \mathrm{~h}$ and $30 \mathrm{~h} \mathrm{pt}$. At $16 \mathrm{~h}$ post infection, cells were trypsinized, fixed with $2 \%$ PFA, and washed. GFP mean fluorescence intensity (MFI) was measured using Cytek Aurora flow cytometer (Cytek Biosciences, Fremont CA).

$\mathrm{CD} 2 \mathrm{v}$ activation of the NF- $\mathrm{B}$ pathway was further examined using flow cytometry assay. PK15 cells were transfected with pCD2v-HA or pORFV113-Flag, fixed with 2\% PFA at $3 \mathrm{~h} \mathrm{pt}$, permeabilized with $0.2 \%$ Triton-X100 and incubated with anti-HA (2367S; Cell Signaling

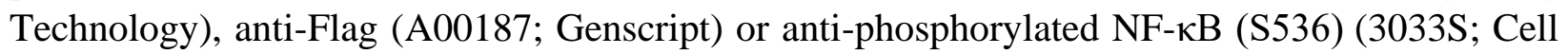
Signaling Technology) for $45 \mathrm{~min}$ on ice. Secondary antibodies were goat anti-rabbit Alexa fluor 488 (A11008; Thermo Scientific) for pNF-kB (S536) and goat anti-mouse Alexa fluor 647 (A21236; Thermo Scientific) for CD2v and ORFV113. pNF- $\kappa B$ (S536) mean fluorescence intensity (MFI) was examined in cells expressing CD2v or ORFV113.

Co-immunoprecipitation. To study the interaction between CD2v and CD58, PK15 cells were co-transfected with pEmpty-HA and pCD58-Flag or pCD2v-HA and pCD58-Flag. Whole cell extracts were prepared at $8 \mathrm{~h}$ pt using RIPA lysis buffer (Thermo Scientific). Reciprocal coimmunoprecipitations were performed using active motif Co-IP kit (Active Motif, Carlsbad, CA) in moderate stringency buffer ( IP High buffer [Active Motif] and Protease inhibitor cocktail [Sigma], without detergent and salt) following the manufacturer's protocol. Whole cell extracts were incubated with HA (3724S; Cell Signaling Technology) and Flag (A00187; Genscript) antibodies overnight at $4^{\circ} \mathrm{C}$, and then pre-washed with $50 \mu \mathrm{l}$ of protein $\mathrm{G}$ agarose bead slurry (Millipore) at $4^{\circ} \mathrm{C}$ for $2 \mathrm{~h}$. Beads were washed four times with moderate stringency buffer and bound proteins were eluted in Laemmli buffer. Whole cell protein extracts and immunoprecipitated products were examined by SDS-PAGE-Western blot with the appropriate antibodies.

Interaction of CD2v with endogenous human CD58 was evaluated in 293T cells transfected with pCD2v-HA. Reciprocal co-immunoprecipitation was performed using anti-HA (3724S; Cell Signaling Technology) and hu-CD58 (sc20009; Santa Cruz) antibodies following the manufacturer's protocol (Active motif Co-IP kit). Immunoprecipitated products were examined 
by SDS-PAGE-Western blot with the appropriate antibodies (7074; Cell Signaling Technology, 7076; Cell Signaling Technology).

Co-localization assays. CD2v-CD58 interaction was examined by confocal microscopy. PK15 cells were co-transfected with pCD2v-HA and pCD58-Flag, fixed with 4\% PFA $24 \mathrm{~h} \mathrm{pt}$, permeabilized with $0.2 \%$ Tritron-X 100 and treated with anti-HA (3724S; Cell Signaling Technology) or anti-Flag (A00187; Genscript) primary antibodies. Cells were then washed with PBS and incubated with goat anti rabbit Alexa fluor 594 (A11012; Cell signaling Technology) and anti-mouse Alexa fluor 488 goat (A11029; Cell Signaling Technology) secondary antibodies for $1 \mathrm{~h}$. Nuclei were stained with DAPI, and images obtained using A1 Nikon confocal microscope. Similarly, co-localization of CD2v with endogenous human CD58 was investigated in 293T cells. Cells were transfected with pCD2v-HA and IFA was performed using anti-HA (3724S; Cell Signaling Technology) and anti-CD58 (sc20009; Santa Cruz) primary antibodies, and goat anti rabbit Alexa fluor 594 (A11012; Cell Signaling Technology) and anti-mouse Alexa fluor 488 goat (A11029) secondary antibodies.

Statistics. All statistical analyses were performed using student's t test. Statistically significant difference were indicated as *, $P<0.05 ; * *, P<0.01$ and NS, not significant.

\section{ACKNOWLEDGEMENTS}

This work was funded by National Pork Board (grant 13-102) and by the USDA National Institute of Food and Agriculture (grant 2013 - 67015-21335).

We thank Hiep Vu (Nebraska Center for Virology, University of Nebraska-Lincoln) for his advice and assistance in generating monoclonal antibodies, Fernando A. Osorio (Nebraska Center for Virology, University of Nebraska-Lincoln) for laboratory support, James F. Lowe (College of Veterinary medicine at University of Illinois at Urbana-Champaign) and Anna Carol Dilger (Department of Animal Sciences at University of Illinois at Urbana-Champaign) for providing swine blood.

\section{REFERENCES}

1. Montgomery RE. 1921. On A Form of Swine Fever Occurring in British East Africa (Kenya Colony). J Comp Pathol Ther 34:159-191.

2. Detray D. 1957. Persistence of viremia and immunity in African swine fever. Am J Vet Res 18:811-816.

3. Oura CA, Powell PP, Anderson E, Parkhouse RM. 1998. The pathogenesis of African swine fever in the resistant bushpig. J Gen Virol 79:1439-1443.

4. Anderson EC, Hutchings GH, Mukarati N, Wilkinson PJ. 1998. African swine fever virus infection of the bushpig (Potamochoerus porcus) and its significance in the epidemiology of the disease. Vet Microbiol 62:1-15.

5. Gómez-Villamandos JC, Bautista MJ, Sánchez-Cordón PJ, Carrasco L. 2013. Pathology of African swine fever: The role of monocyte-macrophage. Virus Res 173:140-149.

6. Moulton J, Coggins L. 1968. Comparison of lesions in acute and chronic African swine fever. Cornell Vet 58:364-388.

7. Blome S, Gabriel C, Beer M. 2013. Pathogenesis of African swine fever in domestic pigs 
and European wild boar. Virus Res 173:122-130.

8. Ramiro-Ibáñez F, Ortega A, Brun A, Escribano JM, Alonso C. 1996. Apoptosis: A mechanism of cell killing and lymphoid organ impairment during acute African swine fever virus infection. J Gen Virol 77:2209-2219.

9. Carrasco L, Bautista MJ, Gómez-Villamandos JC, De Las Mulas JM, De Lara FCM, Wilkinson PJ, Sierra MA. 1997. Development of microscopic lesions in splenic cords of pigs infected with African swine fever virus. Vet Res 28:93-99.

10. Wilkinson PJ, Wardley RC, Williams SM. 1981. African swine fever virus (Malta/78) in pigs. J Comp Pathol 91:277-284.

11. Wardley RC, Hamilton F, Wilkinson PJ. 1979. The replication of virulent and attenuated strains of African swine fever virus in porcine macrophages. Arch Virol 61:217-225.

12. Mebus C. 1988. African swine fever. Adv Virus Res 35:251-269.

568 13. Carrillo C, Borca M V, Afonso CL, Onisk D V, Rock DL. 1994. Long-term persistent

68:580-3.

14. Muñoz-Moreno R, Galindo I, Cuesta-Geijo MÁ, Barrado-Gil L, Alonso C. 2015. Host cell targets for African swine fever virus. Virus Res 209:118-127.

15. Carrasco L, Chacón-M De Lara F, Martín De Las Mulas J, Gómez-Villamandos JC, Hervás J, Wilkinson PJ, Sierra MA. 1996. Virus association with lymphocytes in acute African swine fever. Vet Res 27:305-312.

16. Carrasco L, Chacon-M. de Lara F, Martin de las Mulas J, Gomez-Villamandos JC, Perez J, Wilkinson PJ, Sierra MA. 1996. Apoptosis in lymph nodes in acute African swine fever. J Comp Pathol 115:415-428.

17. Gómez-Villamandos JC, Hervás J, Mendéz A, Carrasco L, Villeda CJ, Wilkinson PJ, Sierra MA. 1995. A pathological study of the perisinusoidal unit of the liver in acute African swine fever. Res Vet Sci 59:146-151.

18. Gómez-Villamandos JC, Hervás J, Moreno C, Carrasco L, Bautista MJ, Caballero JM, Wilkinson PJ, Sierra MA. 1997. Subcellular changes in the tonsils of pigs infected with acute African swine fever virus. Vet Res 28:179-189.

19. Salguero FJ, Sánchez-Cordón PJ, Núñez A, Fernández de Marco M, Gómez-Villamandos JC. 2005. Proinflammatory cytokines induce lymphocyte apoptosis in acute African swine fever infection. J Comp Pathol 132:289-302.

20. Gomez-Villamandos JC, Hervas J, Mendez A, Carrasco L, De las Mulas JM, Villeda CJ, Wilkinson PJ, Sierra MA. 1995. Experimental African swine fever: Apoptosis of lymphocytes and virus replication in other cells. J Gen Virol 76:2399-2405.

21. Gómez del Moral M, Ortuño E, Fernández-Zapatero P, Alonso F, Alonso C, Ezquerra A, Domínguez J. 1999. African swine fever virus infection induces tumor necrosis factor alpha production: implications in pathogenesis. J Virol 73:2173-2180.

22. Salguero FJ, Ruiz-Villamor E, Bautista MJ, Sánchez-Cordón PJ, Carrasco L, GómezVillamandos JC. 2002. Changes in macrophages in spleen and lymph nodes during acute African swine fever: Expression of cytokines. Vet Immunol Immunopathol 90:11-22.

23. Fensterl V, Sen GC. 2009. Interferons and viral infections. BioFactors 35:14-20.

24. Fensterl V, Chattopadhyay S, Sen GC. 2015. No Love Lost Between Viruses and Interferons. Annu Rev Virol 2:549-572.

25. McNab F, Mayer-Barber K, Sher A, Wack A, O’Garra A. 2015. Type I interferons in infectious disease. Nat Rev Immunol 15:87-103. 
26. Katze MG, He Y, Gale M. 2002. Viruses and interferon: A fight for supremacy. Nat Rev Immunol 2:675-687.

27. Nan Y, Nan G, Zhang YJ. 2014. Interferon induction by RNA viruses and antagonism by viral pathogens. Viruses 6:4999-5027.

28. Kim TK, Maniatis T. 1997. The mechanism of transcriptional synergy of an in vitro assembled interferon- $\beta$ enhanceosome. Mol Cell 1:119-129.

29. Lenardo MJ, Fan CM, Maniatis T, Baltimore D. 1989. The involvement of NF- $\mathrm{BB}$ in $\beta$ interferon gene regulation reveals its role as widely inducible mediator of signal transduction. Cell 57:287-294.

30. Thanos D, Maniatis T. 1995. Identification of the rel family members required for virus induction of the human beta interferon gene. Mol Cell Biol 15:152-164.

31. Sato M, Suemori H, Hata N, Asagiri M, Ogasawara K, Nakao K, Nakaya T, Katsuki M, Noguchi S, Tanaka N, Taniguchi T. 2000. Distinct and essential roles of transcription factors IRF-3 and IRF-7 in response to viruses for IFN- $\alpha / \beta$ gene induction. Immunity 13:539-548.

32. Honda K, Takaoka A, Taniguchi T. 2006. Type I Inteferon Gene Induction by the Interferon Regulatory Factor Family of Transcription Factors. Immunity 25:349-360.

33. Chen L, Greene WC. 2004. Shaping the nuclear action of NF-kappaB. Nat Rev Mol Cell Biol 5:392-401.

34. Perkins ND. 2007. Integrating cell-signalling pathways with NF- $\kappa$ B and IKK function. Nat Rev Mol Cell Biol 8:49-62.

35. Scheidereit C. 2006. IkappaB kinase complexes: gateways to NF-kappaB activation and transcription. Oncogene 25:6685-6705.

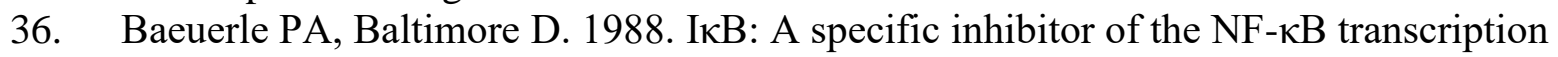
factor. Science 242:540-546.

37. Li C-CH, Dai R-M, Longo DL. 1995. Inactivation of NF-kB Inhibitor IkB: UbiquitinDependent Proteolysis and its Degredation Product. Biochem Biophys Res Commun 215:292-2301.

38. Moschonas A, Ioannou M, Eliopoulos AG. 2012. CD40 Stimulates a "Feed-Forward" NF$\kappa B-D r i v e n$ Molecular Pathway That Regulates IFN- $\beta$ Expression in Carcinoma Cells. J Immunol 188:5521-5527.

39. Balachandran S, Beg AA. 2011. Defining emerging roles for NF- $\kappa B$ in antivirus responses: Revisiting the interferon- $\beta$ Enhanceosome paradigm. PLoS Pathog 7:1-4.

40. Bertolusso R, Tian B, Zhao Y, Vergara L, Sabree A, Iwanaszko M, Lipniacki T, Brasier AR, Kimmel M. 2014. Dynamic cross talk model of the epithelial innate immune response to double-stranded RNA stimulation: Coordinated dynamics emerging from cell-level noise. PLoS One 9.

41. Zhao J, He S, Minassian A, Li J, Feng P. 2015. Recent advances on viral manipulation of NF- $\kappa B$ signaling pathway. Curr Opin Virol 15:103-111.

42. de Oliveira VL, Almeida SCP, Soares HR, Crespo A, Marshall-Clarke S, Parkhouse RM. 2011. A novel TLR3 inhibitor encoded by African swine fever virus (ASFV). Arch Virol 156:597-609.

43. Correia S, Ventura S, Parkhouse RM. 2013. Identification and utility of innate immune system evasion mechanisms of ASFV. Virus Res 173:87-100.

44. Wang X, Wu J, Wu Y, Chen H, Zhang S, Li J, Xin T, Jia H, Hou S, Jiang Y, Zhu H, Guo X. 2018. Inhibition of cGAS-STING-TBK1 signaling pathway by DP96R of ASFV China 
2018/1. Biochem Biophys Res Commun 506:437-443.

45. Revilla Y, Callejo M, Rodrı JM, Culebras E, Nogal L, Salas L, Vin E, Fresno M. 1998. Inhibition of nuclear factor kappaB activation by a virus-encoded IkappaB-like protein. J Biol Chem 273:5405-5411.

46. Afonso CL, Piccone ME, Zaffuto KM, Neilan J, Kutish GF, Lu Z, Balinsky CA, Gibb TR, Bean TJ, Zsak L, Rock DL. 2004. African swine fever virus multigene family 360 and 530 genes affect host interferon response. J Virol 78:1858-1864.

47. Gil S, Sepúlveda N, Albina E, Leitão A, Martins C. 2008. The low-virulent African swine fever virus (ASFV/NH/P68) induces enhanced expression and production of relevant regulatory cytokines (IFN $\alpha, \mathrm{TNF} \alpha$ and IL12p40) on porcine macrophages in comparison to the highly virulent ASFV/L60. Arch Virol 153:1845-1854.

48. Zhang F, Hopwood P, Abrams CC, Downing A, Murray F, Talbot R, Archibald A, Lowden S, Dixon LK. 2006. Macrophage transcriptional responses following in vitro infection with a highly virulent African swine fever virus isolate. J Virol 80:10514-10521.

49. García-Belmonte R, Pérez-Núñez D, Pittau M, Richt JA, Revilla Y. 2019. African Swine Fever Virus Armenia/07 Virulent Strain Controls Interferon Beta Production through the cGAS-STING Pathway. J Virol 93:1-17.

50. Portugal R, Leitão A, Martins C. 2018. Modulation of type I interferon signaling by African swine fever virus (ASFV) of different virulence L60 and NHV in macrophage host cells. Vet Microbiol 216:132-141.

51. Reis AL, Abrams CC, Goatley LC, Netherton C, Chapman DG, Sanchez-Cordon P, Dixon LK. 2016. Deletion of African swine fever virus interferon inhibitors from the genome of a virulent isolate reduces virulence in domestic pigs and induces a protective response. Vaccine 34:4698-4705.

52. Karalyan Z, Zakaryan H, Sargsyan K, Voskanyan H, Arzumanyan H, Avagyan H, Karalova E. 2012. Interferon status and white blood cells during infection with African swine fever virus in vivo. Vet Immunol Immunopathol 145:551-555.

53. Golding JP, Goatley L, Goodbourn S, Dixon LK, Taylor G, Netherton CL. 2016. Sensitivity of African swine fever virus to type I interferon is linked to genes within multigene families 360 and 505. Virology 493:154-161.

54. González S, Mendoza C, Sánchez-Vizcaino JM, Alonso F. 1990. Inhibitory effect of African swine fever virus on lectin-dependent swine lymphocyte proliferation. Vet Immunol Immunopathol 26:71-80.

55. Borca M V, Carrillo C, Zsak L, Laegreid WW, Kutish GF, Neilan JG, Burrage TG, Rock DL. 1998. Deletion of a CD2-like gene, 8-DR, from African swine fever virus affects viral infection in domestic swine. J Virol 72:2881-2889.

56. Rodríguez JM, Yáñez RJ, Almazán F, Viñuela E, Rodriguez JF. 1993. African swine fever virus encodes a CD2 homolog responsible for the adhesion of erythrocytes to infected cells. J Virol 67:5312-5320.

57. Borca M V., Kutish GF, Afonso CL, Irusta P, Carrillo C, Brun A, Sussman M, Rock DL. 1994. An African Swine Fever Virus Gene with Similarity to the T-Lymphocyte Surface Antigen CD2 Mediates Hemadsorption. Virology 199:463-468.

58. Bockenstedt LK, Goldsmith MA, Dustin M, Olive D, Springer TA, Weiss A. 1988. The CD2 ligand LFA-3 activates T cells but depends on the expression and function of the antigen receptor. J Immunol 141:1904-1911.

59. Satiimul T. 1988. Accessory Cell-Dependent T-Cell Activation via Involvement of CD2- 
LFA-3 Interaetions. Scand J Immunol 28:277-284.

696

697

698

699

700

701

702

703

704

705

706

707

708

709

710

711

712

713

714

715

716

717

718

719

720

721

722

723

724

725

726

727

728

729

730

731

732

733

734

735

736

737

738

739
60. Karmann K, Hughes CCW, Fanslow WC, Pober JS. 1996. Endothelial cells augment the expression of CD40 ligand on newly activated human CD4+T cells through a CD2/LFA-3 signaling pathway. Eur J Immunol 26:610-617.

61. Diaz-Sanchez D, Chegini S, Zhang K, Saxon A. 2018. CD58 (LFA-3) stimulation provides a signal for human isotype switching and IgE production distinct from CD40. J Immunol 153:10-20.

62. King PD, Sadra A, Han A, Liu XR, Sunder-Plassmann R, Reinherz EL, Dupont B. 1996. CD2 signaling in $T$ cells involves tyrosine phosphorylation and activation of the Tec family kinase, EMT/ITK/TSK. Int Immunol 8:1707-1714.

63. Lin H, Hutchcroft JE, Andoniou CE, Kamoun M, Band H, Bierer BE. 1998. Association of p59 fyn with the T Lymphocyte Costimulatory Receptor CD2. Binding of the Fyn Src homology (SH)3 domain is regulated by the Fyn SH2 domain. J Biol Chem 273:1991419921.

64. Le Guiner S, Le Dréan E, Labarrière N, Fonteneau JF, Viret C, Diez E, Jotereau F. 1998. LFA-3 co-stimulates cytokine secretion by cytotoxic T lymphocytes by providing a TCRindependent activation signal. Eur J Immunol 28:1322-1331.

65. Meinl E, Lengenfelder D, Blank N, Pirzer R, Barata L, Hivroz C. 2000. Differential Requirement of ZAP-70 for CD2-Mediated Activation Pathways of Mature Human T Cells. J Immunol 165:3578-3583.

66. Ariel O, Levi Y, Hollander N. 2009. Signal transduction by CD58: the transmembrane isoform transmits signals outside lipid rafts independently of the GPI-anchored isoform. Cell Signal 21:1100-1108.

67. Skånland SS, Moltu K, Berge T, Aandahl EM, Taskén K. 2014. T-cell co-stimulation through the CD2 and CD28 co-receptors induces distinct signalling responses. Biochem $\mathrm{J}$ 460:399-410.

68. Meier WA, Galeota J, Osorio FA, Husmann RJ, Schnitzlein WM, Zuckermann FA. 2003. Gradual development of the interferon- $\gamma$ response of swine to porcine reproductive and respiratory syndrome virus infection or vaccination. Virology 309:18-31.

69. Parida R, Choi IS, Peterson DA, Pattnaik AK, Laegreid W, Zuckermann FA, Osorio FA. 2012. Location of T-cell epitopes in nonstructural proteins 9 and 10 of type-II porcine reproductive and respiratory syndrome virus. Virus Res 169:13-21.

70. Diel DG, Delhon G, Luo S, Flores EF, Rock DL. 2010. A Novel Inhibitor of the NF-אB Signaling Pathway Encoded by the Parapoxvirus Orf Virus. J Virol 84:3962-3973.

71. Malogolovkin A, Burmakina G, Tulman ER, Delhon G, Diel DG, Salnikov N, Kutish GF, Kolbasov D, Rock DL. 2015. African swine fever virus CD2v and C-type lectin gene loci mediate serological specificity. J Gen Virol 96:866-873.

72. Goatley LC, Dixon LK. 2011. Processing and Localization of the African Swine Fever Virus CD2v Transmembrane Protein. J Virol 85:3294-3305.

73. Kay-Jackson PC, Goatley LC, Cox L, Miskin JE, Parkhouse RM, Wienands J, Dixon LK. 2004. The CD2v protein of African swine fever virus interacts with the actin-binding adaptor protein SH3P7. J Gen Virol 85:119-130.

74. Ruíz-Gonzalvo F, Coll JM. 1993. Characterization of a soluble hemagglutinin induced in African swine fever virus-infected cells. Virology 196:769-777.

75. Monteagudo PL, Lacasta A, López E, Bosch L, Collado J, Pina-pedrero S, Correa-fiz F, Accensi F. 2017. A71 $\triangle$ CD2: a New Recombinant Live Attenuated African Swine Fever 
Virus with Cross-Protective Capabilities. J Virol 91:1-17.

76. Barbalat R, Lau L, Locksley RM, Barton GM. 2009. Toll-like receptor 2 on inflammatory monocytes induces type $\mathrm{i}$ interferon in response to viral but not bacterial ligands. Nat Immunol 10:1200-1209.

77. Bauernfeind F, Hornung V. 2009. Tlr2 joins the interferon gang. Nat Immunol 10:11391141.

78. Kurt-Jones EA, Popova L, Kwinn L, Haynes LM, Jones LP, Tripp RA, Walsh EE, Freeman MW, Golenbock DT, Anderson LJ, Finberg RW. 2000. Pattern recognition receptors TLR4 and CD14 mediate response to respiratory syncytial virus. Nat Immunol $1: 398-401$.

79. Georgel P, Jiang Z, Kunz S, Janssen E, Mols J, Hoebe K, Bahram S, Oldstone MBA, Beutler B. 2007. Vesicular stomatitis virus glycoprotein $\mathrm{G}$ activates a specific antiviral Toll-like receptor 4-dependent pathway. Virology 362:304-313.

80. Pérez-Núñez D, García-Urdiales E, Martínez-Bonet M, Nogal ML, Barroso S, Revilla Y, Madrid R. 2015. CD2v interacts with Adaptor Protein AP-1 during African swine fever infection. PLoS One 10:1-19.

81. Borca MV, O'Donnell V, Holinka LG, Risatti GR, Ramirez-Medina E, Vuono EA, Shi J, Pruitt S, Rai A, Silva E, Velazquez-Salinas L, Gladue DP. 2020. Deletion of CD2-like gene from the genome of African swine fever virus strain Georgia does not attenuate virulence in swine. Sci Rep 10:1-8.

82. Chapman DAG, Tcherepanov V, Upton C, Dixon LK. 2008. Comparison of the genome sequences of non-pathogenic and pathogenic African swine fever virus isolates. J Gen Virol 89:397-408.

83. Rowlands RJ, Duarte MM, Boinas F, Hutchings G, Dixon LK. 2009. The CD2v protein enhances African swine fever virus replication in the tick vector, Ornithodoros erraticus. Virology 393:319-328.

84. Kleiboeker SB, Burrage TG, Scoles GA, Fish D, Rock DL. 1998. African swine fever virus infection in the argasid host, Ornithodoros porcinus porcinus. J Virol 72:1711-1724.

85. Argilaguet JM, Pérez-Martín E, Nofrarías M, Gallardo C, Accensi F, Lacasta A, Mora M, Ballester M, Galindo-Cardiel I, López-Soria S, Escribano JM, Reche PA, Rodríguez F. 2012. DNA Vaccination Partially Protects against African Swine Fever Virus Lethal Challenge in the Absence of Antibodies. PLoS One 7:1-11.

86. Takamatsu HH, Denyer MS, Lacasta A, Stirling CMA, Argilaguet JM, Netherton CL, Oura CA, Martins C, Rodríguez F. 2013. Cellular immunity in ASFV responses. Virus Res 173:110-121.

87. Burmakina G, Malogolovkin A, Tulman ER, Xu W, Delhon G, Kolbasov D, Rock DL. 2019. Identification of T-cell epitopes in African swine fever virus CD2v and C-type lectin proteins. J Gen Virol 100:259-265.

88. Burmakina G, Malogolovkin A, Tulman ER, Zsak L, Delhon G, Diel DG, Shobogorov NM, Morgunov YP, Morgunov SY, Kutish GF, Kolbasov D, Rock DL. 2016. African swine fever virus serotype-specific proteins are significant protective antigens for African swine fever. J Gen Virol 97:1670-1675. 


FIG 1. Subcellular localization and characterization of ASFV CD2v protein. (A) PK15 cells were mock transfected or transfected with a plasmid expressing HA-tagged ASFV CD2v, fixed at various times post transfection $(\mathrm{pt})$, incubated with anti-HA primary antibody, sequentially stained with Alexa fluor 488-labeled secondary antibody and DAPI, and examined by confocal microscopy. Results are representative of two independent experiments. (B) CD2v-HAexpressing PK15 cells hemadsorbed swine red blood cells (RBCs). PK15 cells were transfected with plasmid pCD2v-HA for $24 \mathrm{~h}$, incubated with swine RBCs overnight, and observed with the microscope (X100). CD2v-dependent rosetting is indicated by the arrowheads. Results are representative of two independent experiments.

799

800 

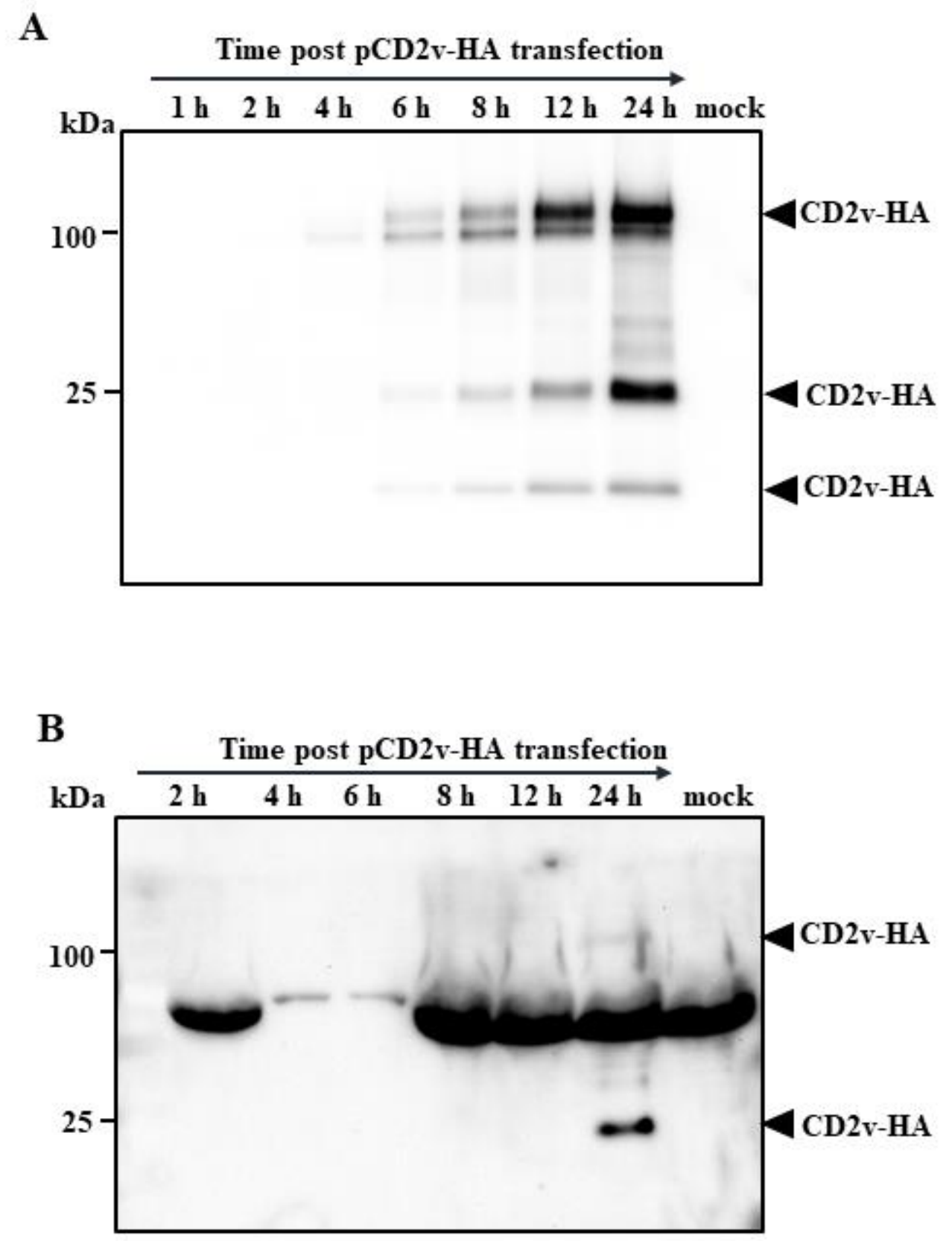

FIG 2. Expression kinetics and secretion of CD2v. (A) PK15 cells mock transfected or transfected with plasmid pCD2v-HA were harvested at the indicated times post transfection. Total cell protein extracts were resolved by SDS-PAGE, blotted and incubated with antibodies against HA. Results are representative of two independent experiments. (B) Detection of CD2v in culture supernatant of PK15 cells transiently expressing CD2v. PK15 cells were transfected as above, and supernatants harvested at various times pt. Cleared supernatants (50 $\mu 1)$ were resolved by SDS-PAGE and analyzed by Western blot using antibodies against HA. Results are representative of two independent experiments. 
A

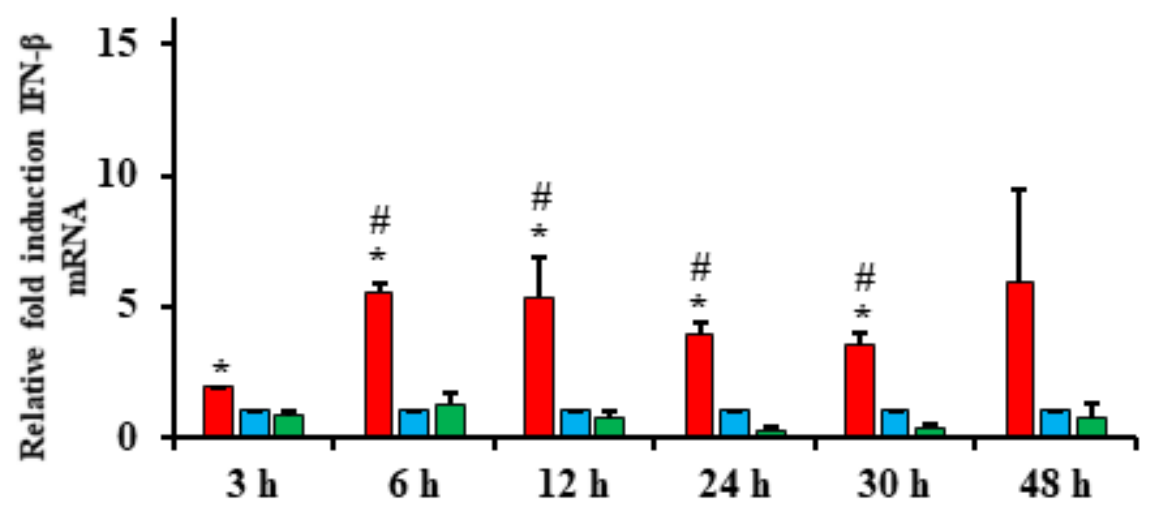

$\square \mathrm{CD} 2 \mathrm{v}-\mathrm{HA} \quad \square$ Empty-HA $\square$ ORFV120

B
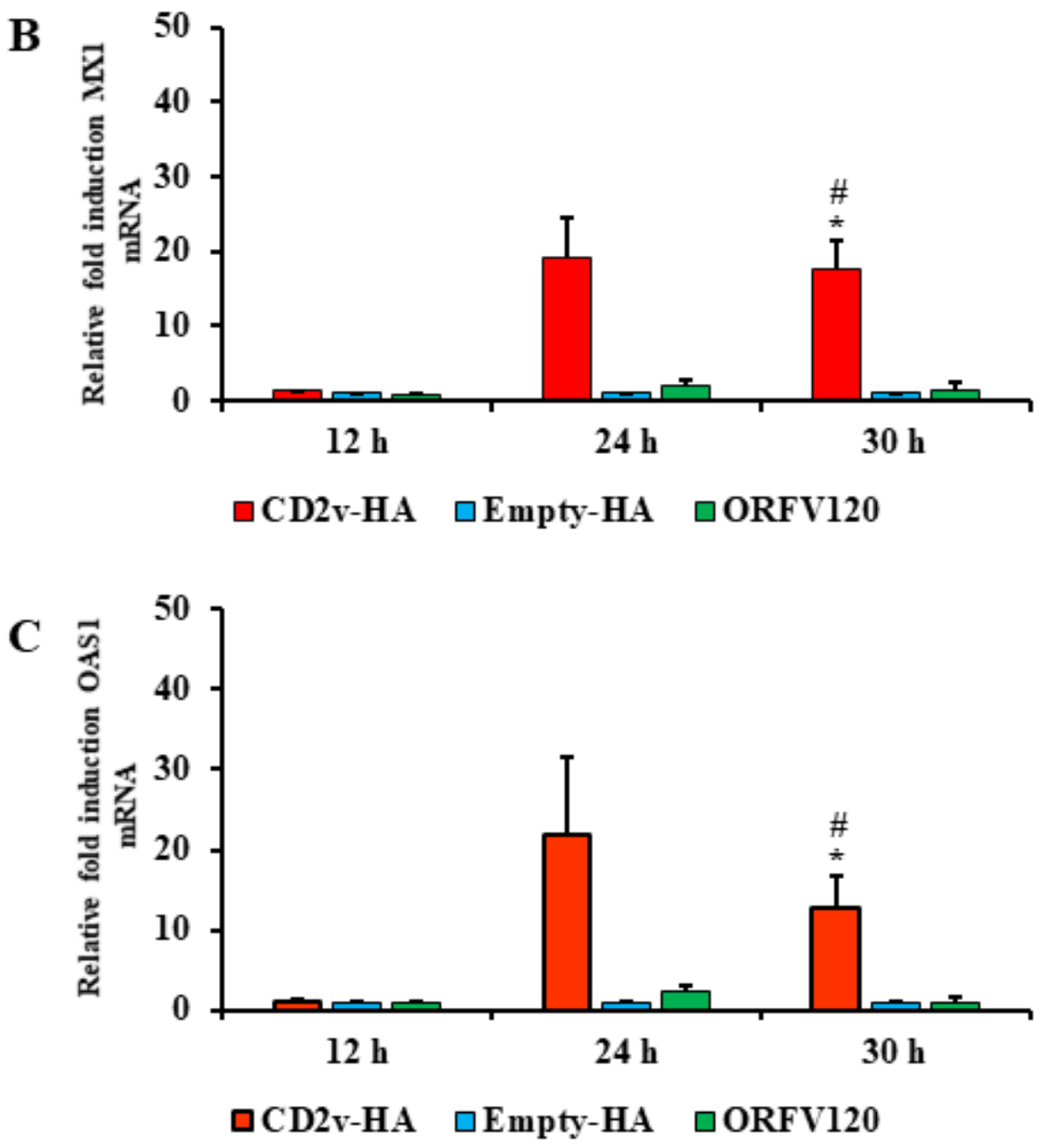

812

813

814

815 
816 FIG 3. Induction of IFN- $\beta$ and ISGs in CD2v-expressing cells. PK15 cells were transfected 817 with plasmids pCD2v-HA, pEmpty-HA or pORFV120-Flag, and transcription of IFN- $\beta$ and 818 selected ISGs were assessed by real-time PCR. (A) Fold changes of IFN- $\beta$ levels in cells 819 transfected with pCD2v-HA relative to pEmpty-HA and pORFV120-Flag at various times post 820 transfection (pt). Results are average mRNA levels from three independent experiments. $P$ 821 values relative to Empty-HA and ORFV120 were 0.007 and $0.1(3 \mathrm{~h}) ; 0.04$ and 0.01 (6 h); 0.016 822 and $0.017(12 \mathrm{~h}) ; 0.015$ and $0.006(24 \mathrm{~h})$; and 0.019 and $0.006(30 \mathrm{~h})$, respectively. (B and C) 823 Fold changes of ISG mRNA levels at $12 \mathrm{~h}, 24 \mathrm{~h}$ and $30 \mathrm{~h}$ pt. Results are average mRNA levels 824 from three independent experiments. $P$-values relative to Empty-HA and ORFV120 at $30 \mathrm{~h} \mathrm{pt}$ 825 were 0.02 and 0.018 for $M X 1$ (B) and 0.04 and 0.037 for OAS1 (C). * and \# denote statistical 826 significance compared to Empty-HA and ORFV120, respectively. 
A

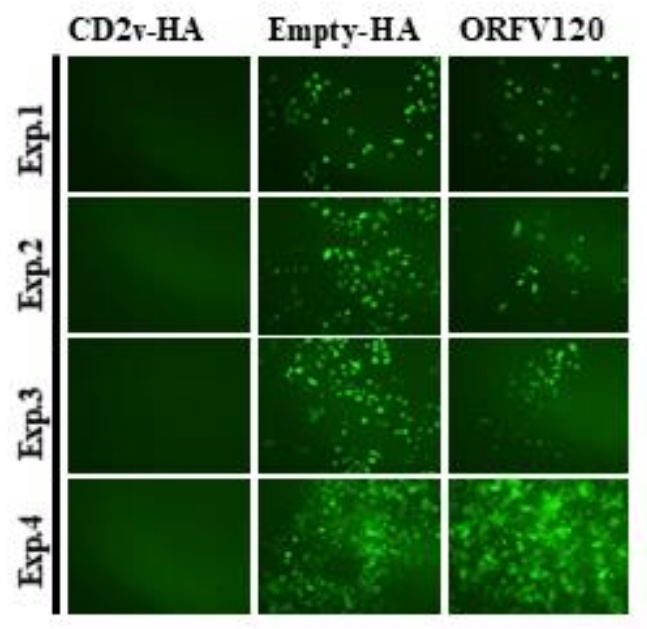

B

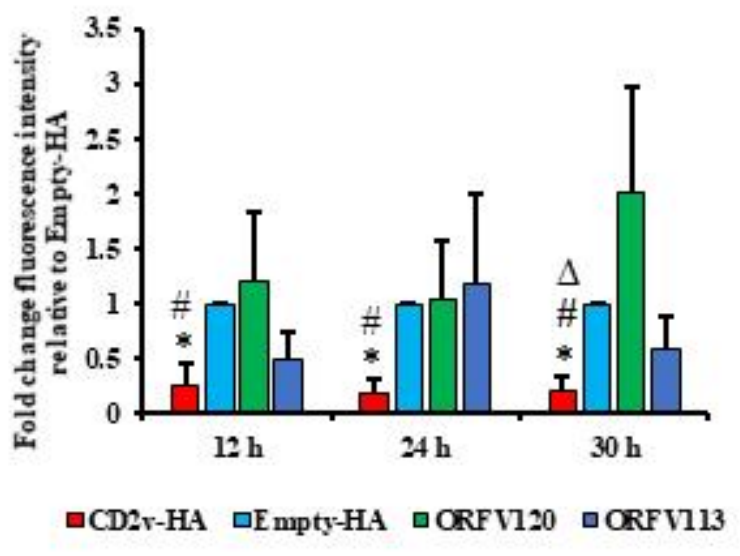

C

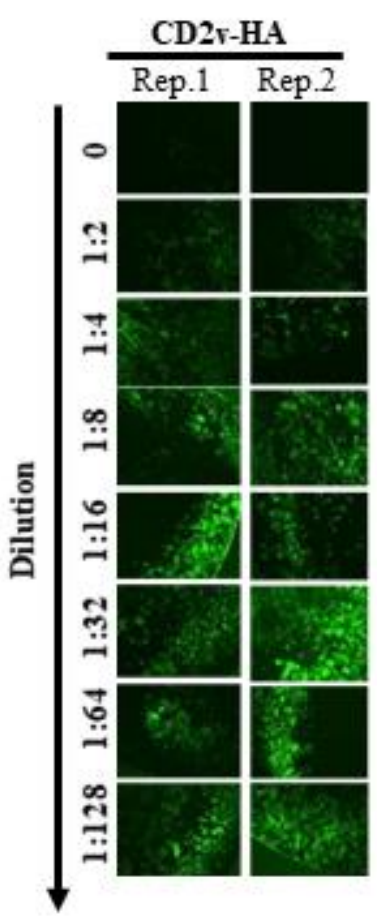

Empty-HA

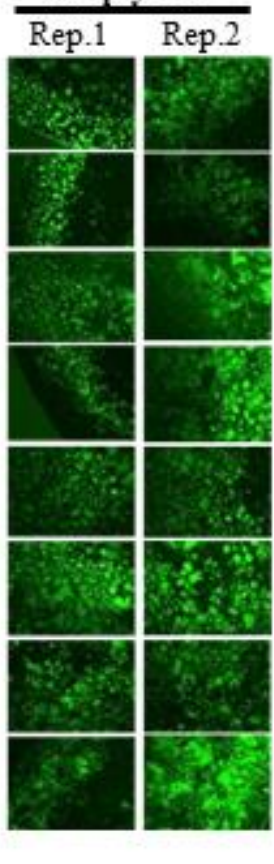

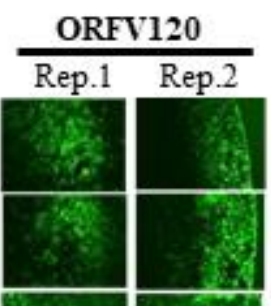
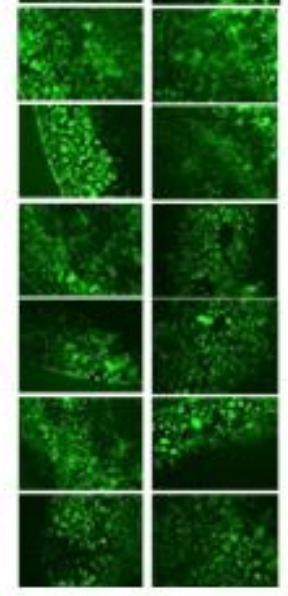

Poly I:C

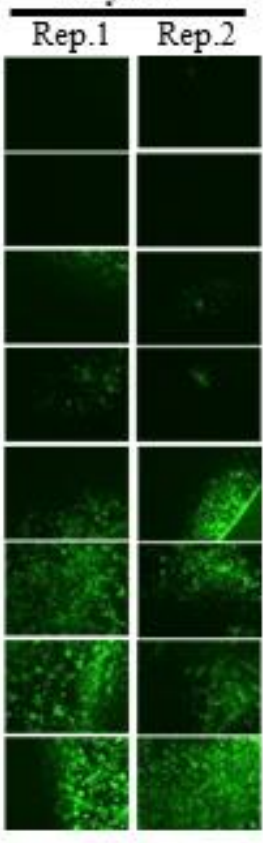


832 FIG 4. Induction of antiviral state in CD2v-expressing cells. PK15 cells were transfected with 833 pCD2v-HA, pEmpty-HA, pORFV120-Flag or pORFV113-Flag. At $12 \mathrm{~h}, 24 \mathrm{~h}$ or $30 \mathrm{~h}$ post transfection, cultures were infected with vesicular stomatitis virus expressing GFP (VSV GFP, 50 PFU/well). (A) Fluorescence microscopy images taken at $16 \mathrm{~h}$ post infection. Note decreased VSV replication in cells transfected with pCD2v-HA relative to controls. Results representative of four independent experiments. Exp., denotes experimental replicates. (B) Mean GFP fluorescence measured by flow cytometry at $16 \mathrm{~h}$ post infection. Results are mean values of four independent experiments. $P$-values relative to transfection with plasmids pEmpty-HA, pORFV120-Flag and pORFV113-Flag were 0.0064, 0.042 and 0.096 (12 h); 0.0002, 0.041 and

$8410.07(24 \mathrm{~h})$; and $0.0002,0.02$ and $0.02(30 \mathrm{~h})$, respectively. *, \# and $\Delta$ denote statistical

842 significance compared to Empty-HA, ORFV120 and ORFV113, respectively. (C) PK15 cells

843 were treated with supernatants obtained from cultures transfected with pCD2v-HA, pEmpty-HA

844 or pORFV120-Flag, or with poly I: C, and infected with VSV ${ }^{\mathrm{GFP}}$ (50 PFU/well) $30 \mathrm{~h}$ post

845 treatment. Fluorescence microscopy images taken at $16 \mathrm{~h}$ post infection are shown. Results

846 representative of two independent experiments. Rep., denotes technical replicates. 
A

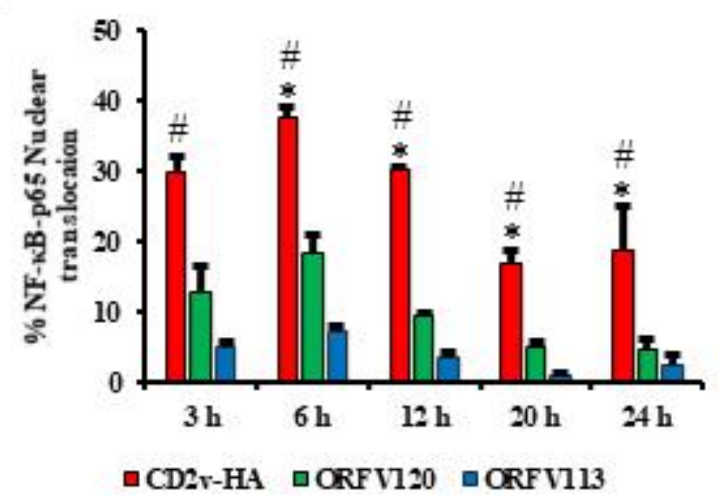

B
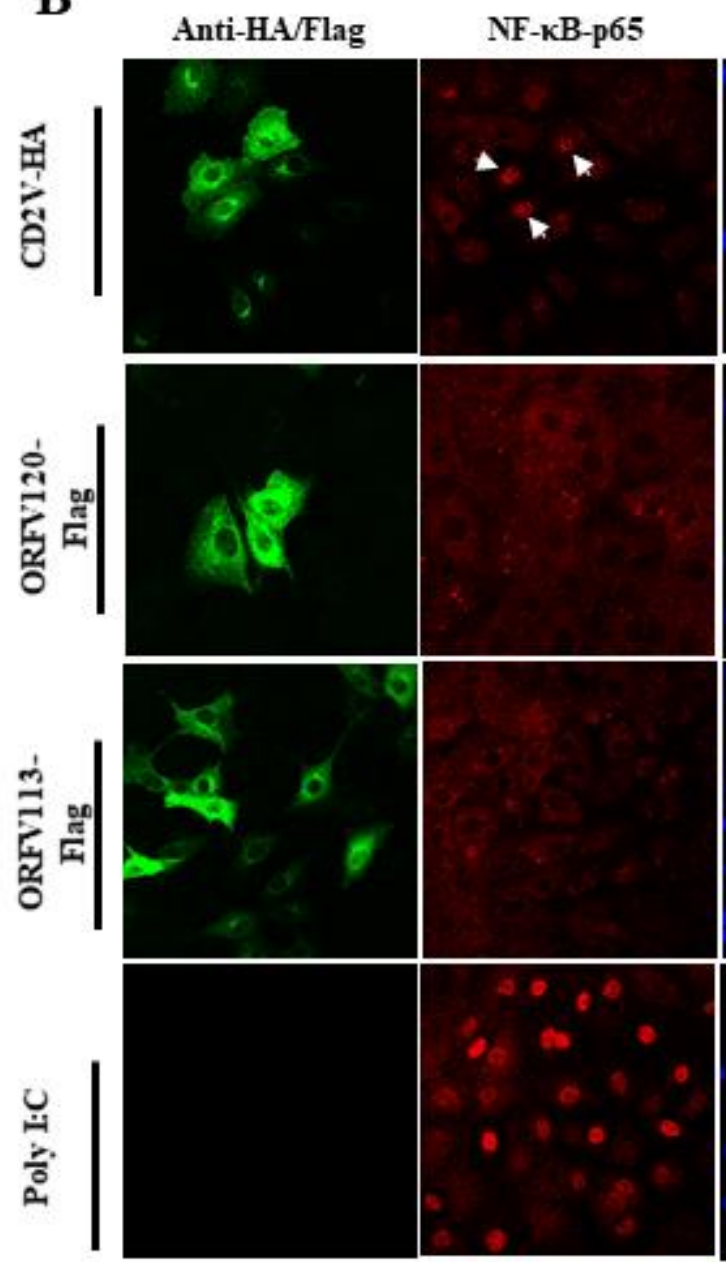

C

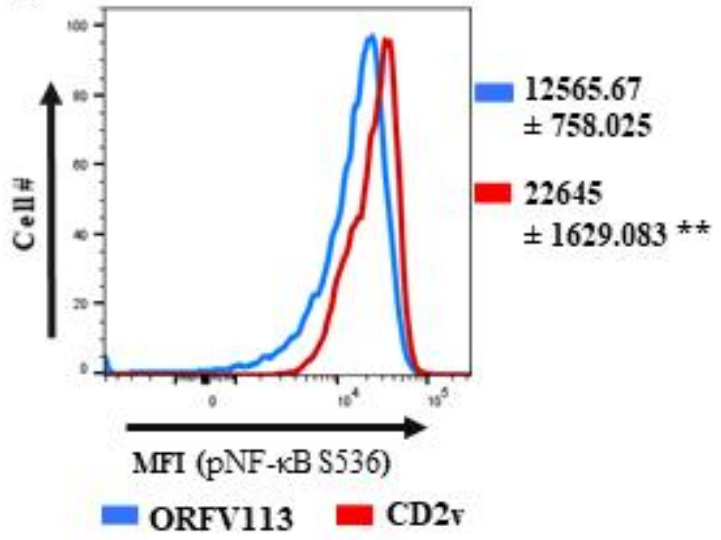

DAPI

Merge
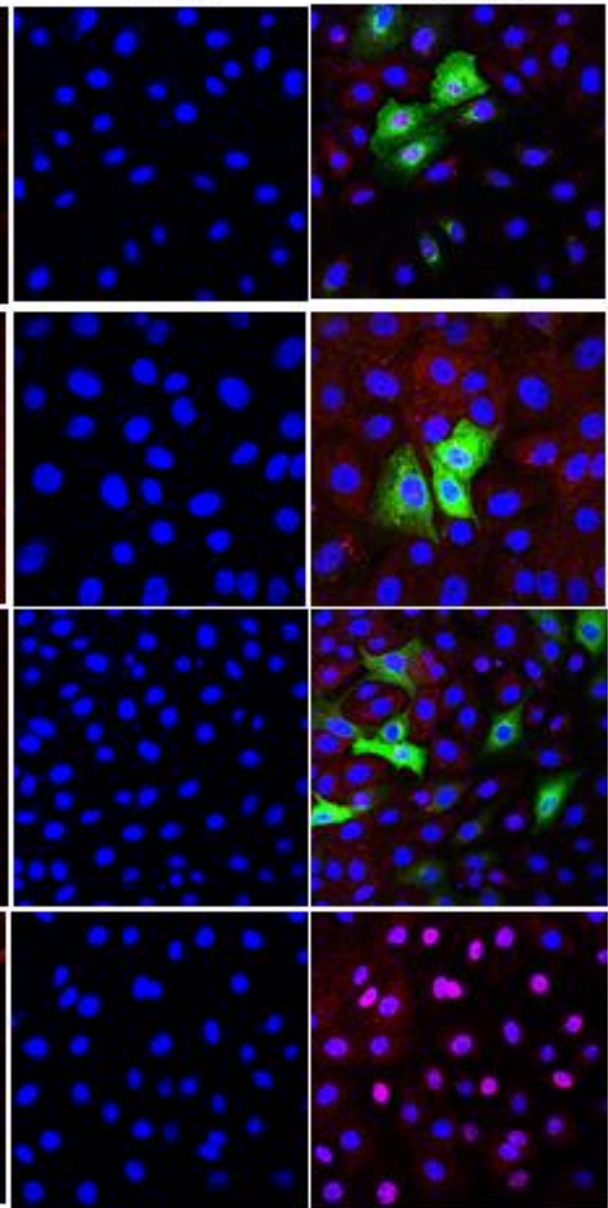
853 FIG 5. Induction of NF-kB-p65 nuclear translocation in CD2v-expressing cells. PK15 cells 854 were transfected with pCD2v-HA, pORFV120-Flag or pORFV113-Flag, processed for 855 immunofluorescence using primary antibodies against HA or Flag and NF- $\kappa$ B-p65, and 856 secondary antibodies Alexa fluor 488 to detect CD2v, ORFV120 or ORFV113 and Alexa fluor 857594 to detect NF- $\mathrm{kB}-\mathrm{p} 65$, and counterstained with DAPI. Cells were counted from 15 random 858 fields/slide (approximately 100 cells/slide) and results, shown as percentage of cells with nuclear 859 NF- $\kappa$ B-p65, are mean values from three independent experiments. (A) Percentage of NF- $\kappa$ B-p65

860 nuclear translocation following the different treatments. $P$-values relative to ORFV120 and

861 ORFV113 were 0.056 and $0.009(3 \mathrm{~h}) ; 0.01$ and $0.0006(6 \mathrm{~h}) ; 0.019$ and $0.02(12 \mathrm{~h}) ; 0.005$ and $8620.004(20 \mathrm{~h})$; and 0.016 and $0.009(24 \mathrm{~h})$, respectively. * and \# denote statistical significance 863 compared to ORFV120 and ORFV113, respectively. (B) Confocal microscopy images showing 864 NF- $\mathrm{BB}-\mathrm{p} 65$ nuclear translocation at $3 \mathrm{~h}$ post transfection (pt; arrows). Green, CD2v or ORFV120

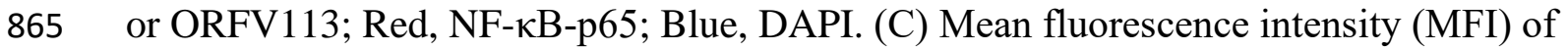
866 phosphorylated NF- $\mathrm{B}$ (S536) fluorescence measured by flow cytometry in CD2v and ORFV113 867 expressing cells at $3 \mathrm{~h} \mathrm{pt}$. Results representative of three independent experiments. $P$-value 868 relative to ORFV113 is 0.0082 . 

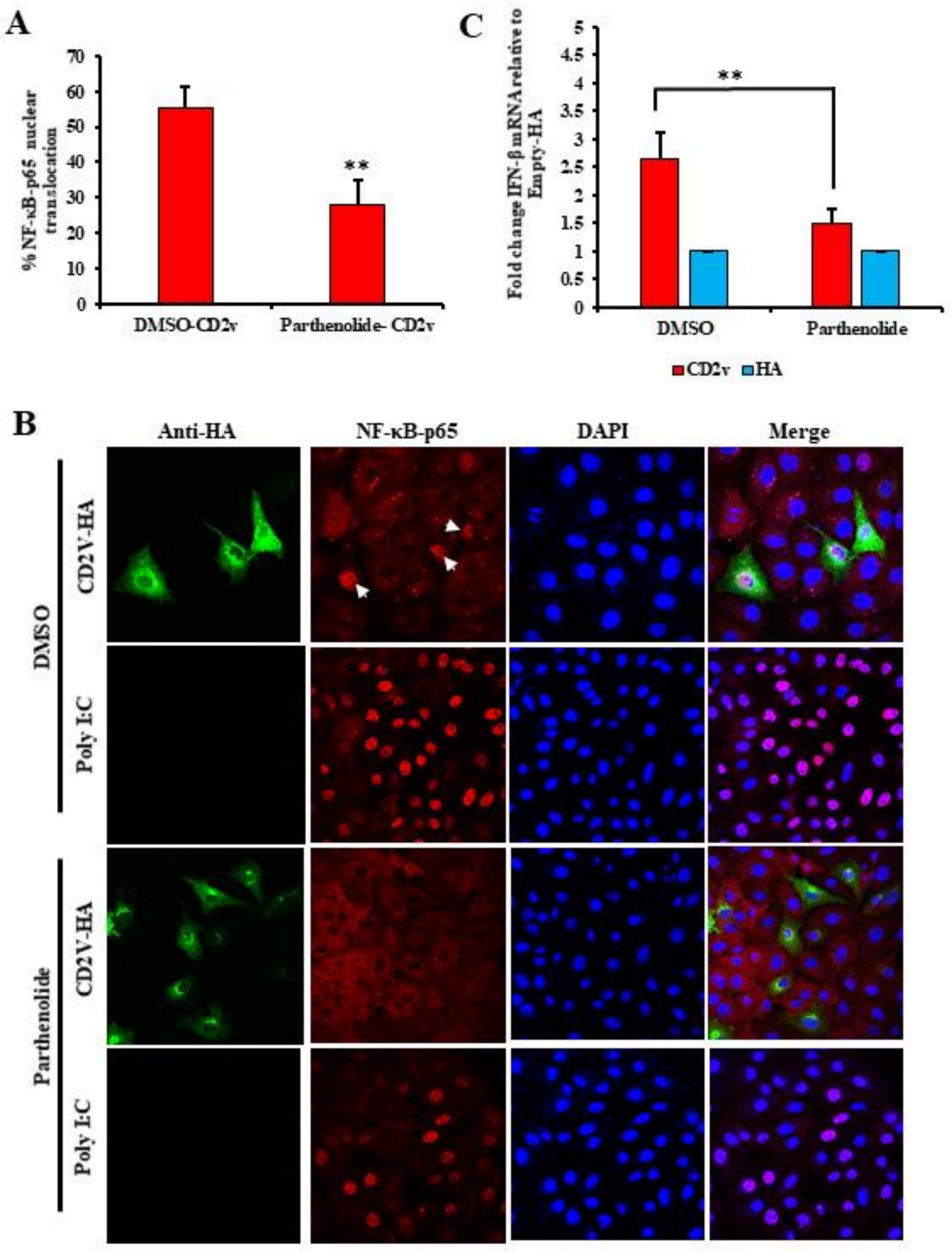
875 FIG 6. CD2v expression induces IFN- $\beta$ transcription in NF- $\kappa B$ dependent manner in PK15

876 cells. PK15 cells pretreated with the NF- $\kappa$ B inhibitor parthenolide $(1 \mu \mathrm{M})$ or DMSO (vehicle

877 control) for one hour, were transfected with pCD2v-HA, fixed at $3 \mathrm{~h}$ post transfection and

878 processed for immunofluorescence with antibodies against HA and NF- $\kappa B-p 65$. Cells were

879 counted from 15 random fields/slide (approximately 100 cells/slide) (A) Percentage of CD2v-

880 expressing cells with nuclear NF- $\mathrm{kB}-\mathrm{p} 65$. Results are expressed as mean values from three

881 independent experiments $(P=0.001)$. (B) Representative confocal images of cells treated as

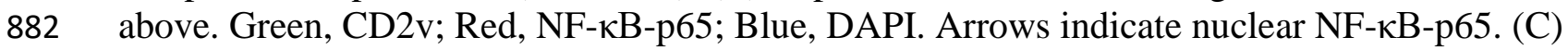

883 PK15 cells treated with parthenolide $(1 \mu \mathrm{M})$ or DMSO for one hour, were transfected with

884 pCD2v-HA in presence or absence of parthenolide. Total RNA was extracted at $6 \mathrm{~h}$ pt, cDNA

885 prepared and IFN- $\beta$ transcription assessed by RT-PCR. Fold changes relative to Empty-HA and

886 data are means from four independent experiments $(P=0.008) .(*, P<0.05 ; * *, P<0.01)$.

887 
A

Input:

Whole cell lysate
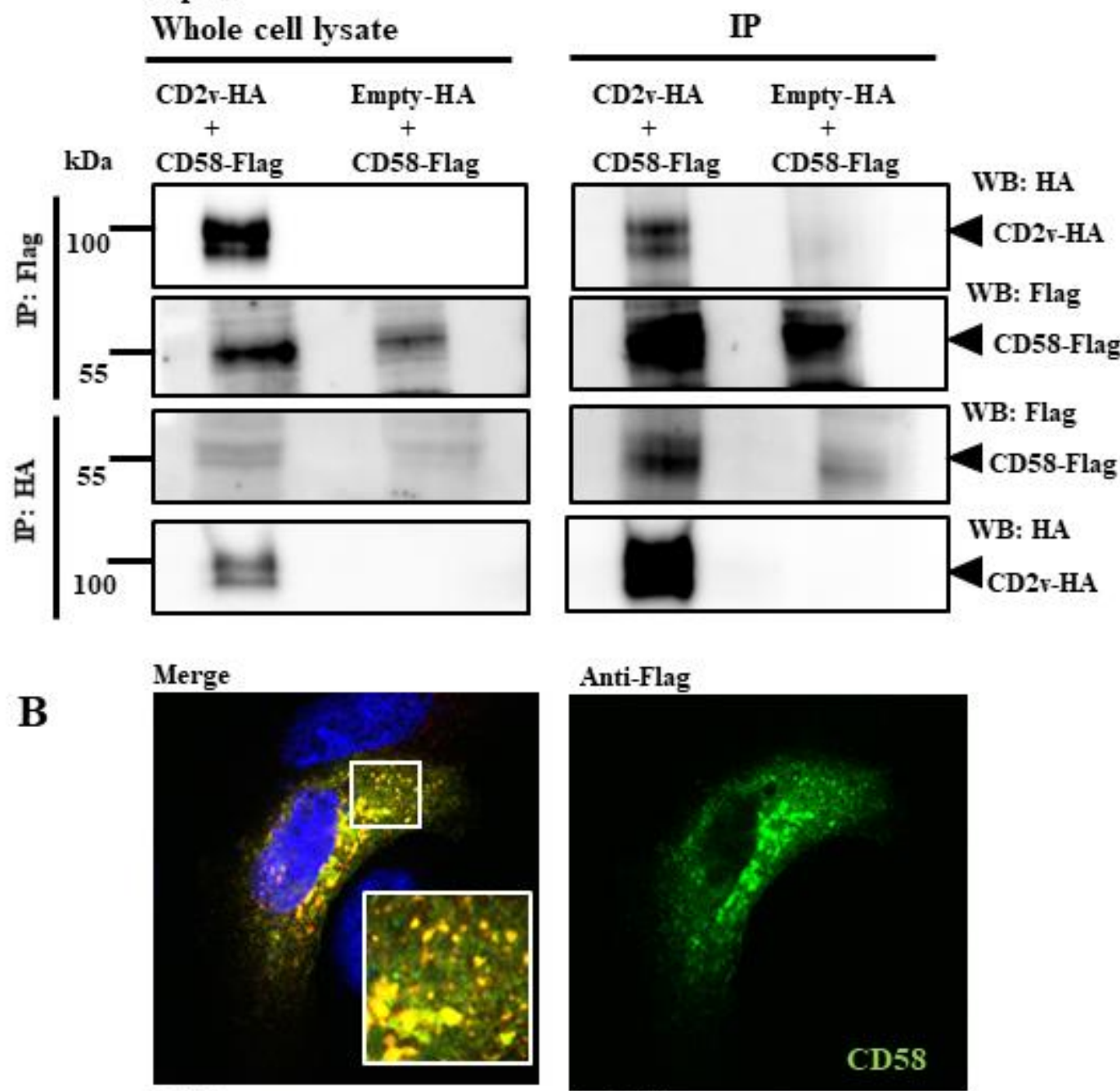

Anti-Flag
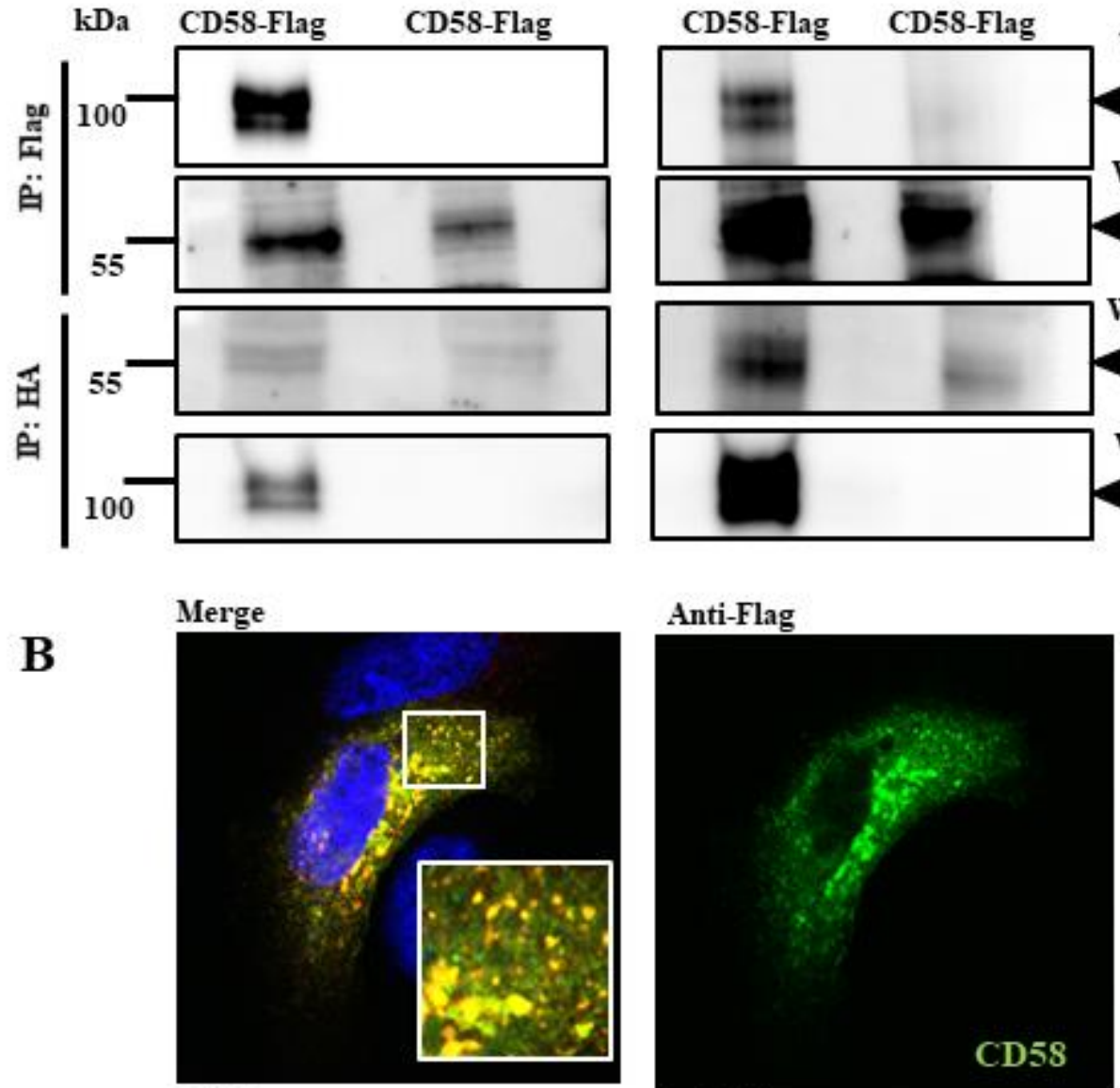

\section{DAPI}

\section{Anti-HA}
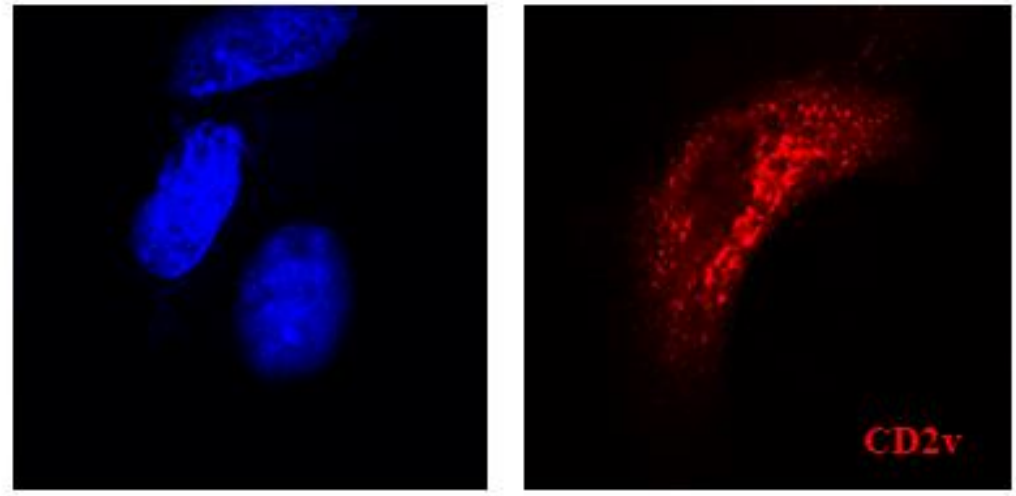
893 FIG 7. Interaction between CD2v and porcine CD58. (A) For co-immunoprecipitation 894 experiments, PK15 cells were co-transfected with plasmids pCD58-Flag and pCD2v-HA, or 895 pCD58-Flag and pEmpty-HA (control) and harvested at $8 \mathrm{~h}$ post transfection (pt). Whole cell 896 lysates (left) and extracts immunoprecipitated with anti-Flag antibodies (IP, two top panels) or 897 anti-HA (IP, two bottom panels) were examined by Western blotting with antibodies directed 898 against proteins indicated on the right. Results are representative of three independent experiments. (B) For co-localization studies, PK15 cells were co-transfected with pCD58-Flag and pCD2v-HA, fixed at $24 \mathrm{~h} \mathrm{pt}$, incubated with mouse anti-Flag and rabbit anti-HA primary

901 antibodies, washed, and incubated with secondary antibodies (Alexa-fluor 488-labeled anti902 mouse and Alexa-fluor 594-labeled anti-rabbit). Cells were counterstained with DAPI, and 903 examined with the confocal microscope. Results are representative of three independent experiments. Insets show magnified areas of the field.

905 
A Input:
Whole cell lysate
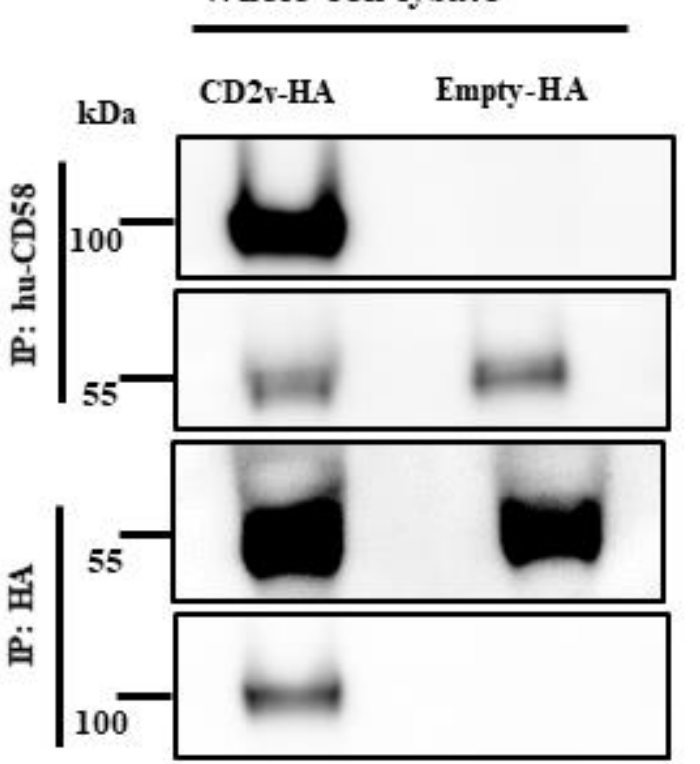

B

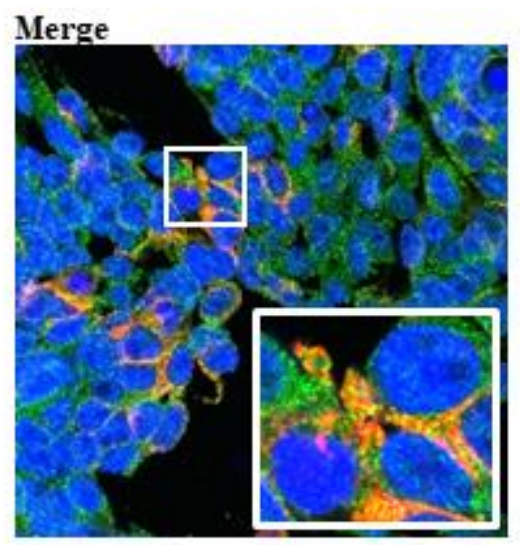

\section{DAPI}
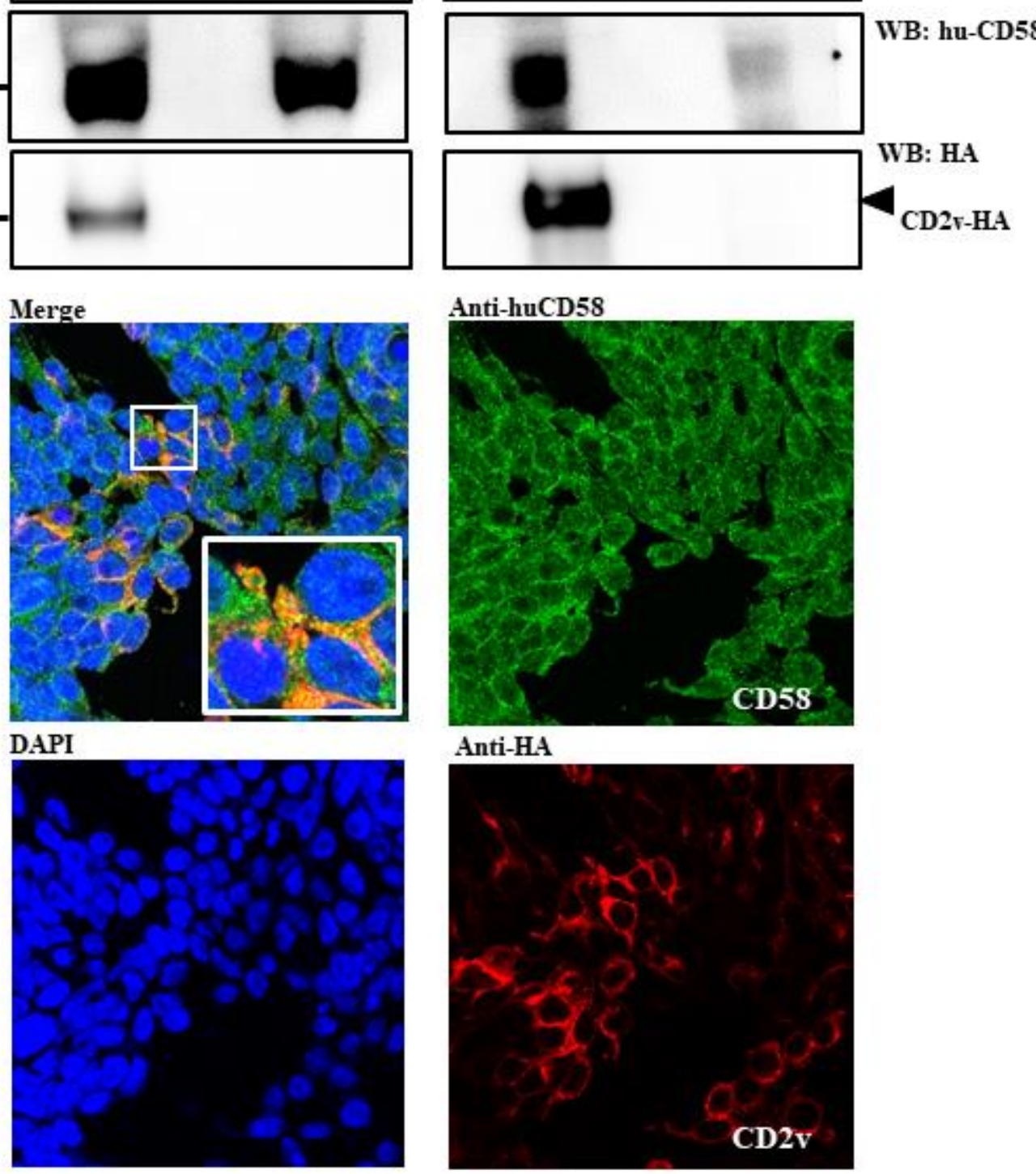

Anti-HA

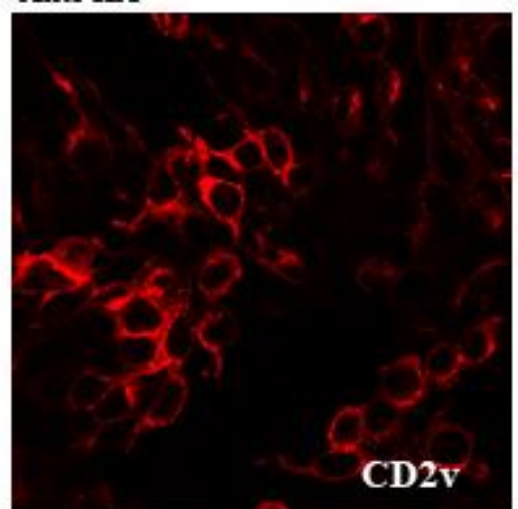

WB: HA

CD2r-HA

WB: hu-CD58

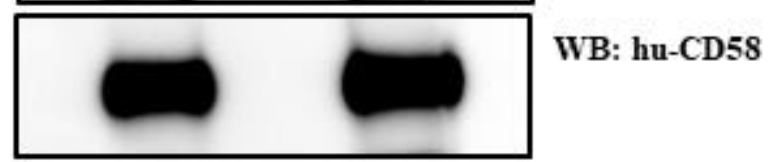

WB: hu-CD58

907

908

909

910 
911 FIG 8. Interaction between CD2v and human CD58. (A) For co-immunoprecipitation, 293T 912 cells were transfected with pCD2v-HA or pEmpty-HA (control) and harvested at $8 \mathrm{~h}$ pt. Whole 913 cell lysates (left) and extracts immunoprecipitated with mouse anti-huCD58 antibodies (IP, two 914 top panels) or anti-HA (IP, two bottom panels) were examined by Western blotting with 915 antibodies directed against proteins indicated on the right. Results are representative of three 916 independent experiments. (B) For co-localization, 293 T cells were transfected with pCD2v-HA, 917 fixed at $24 \mathrm{~h} \mathrm{pt}$, incubated with mouse anti-huCD58 and rabbit anti-HA primary antibodies, 918 washed, and incubated with Alexa-fluor 488-labeled anti-mouse and Alexa-fluor 594-labeled 919 anti-rabbit secondary antibodies. Cells were counter stained with DAPI, and examined with the 920 confocal microscope. Results are representative of three independent experiments. Insets show 921 magnified areas of the field. 
A

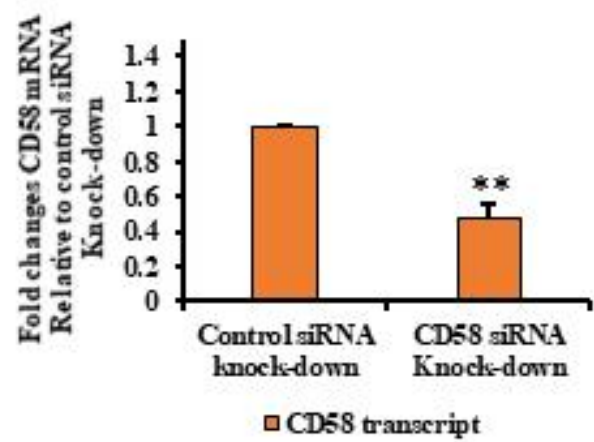

B

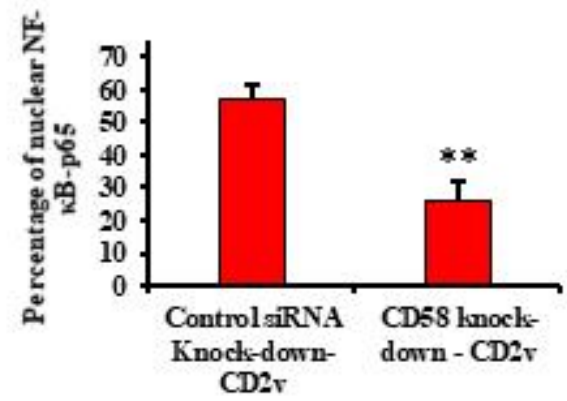

C
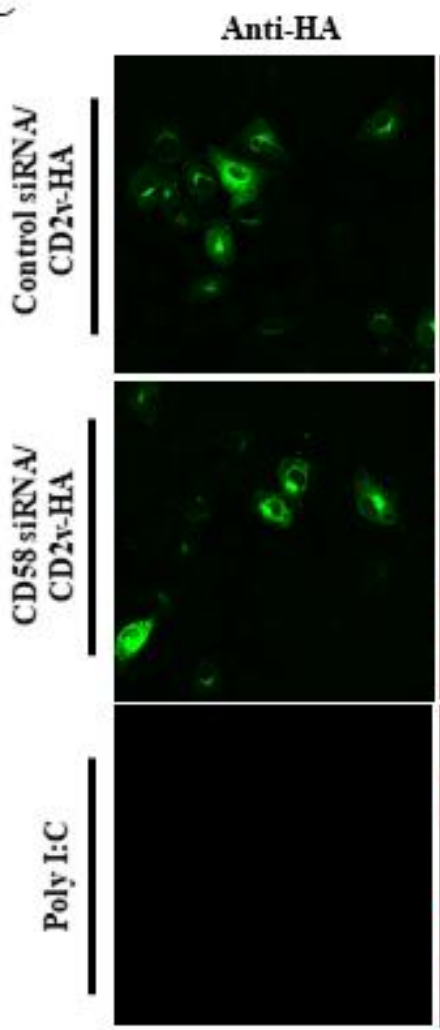

D

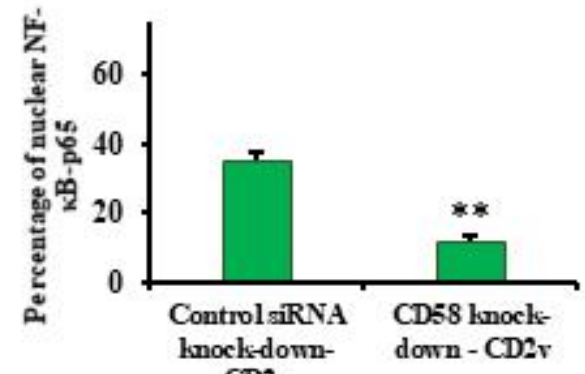

E

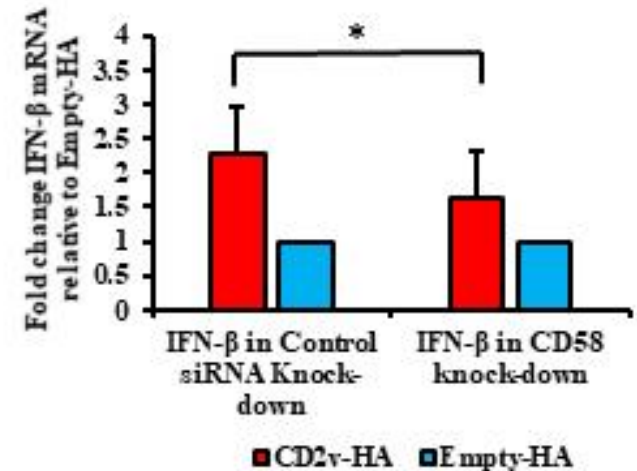


FIG 9. CD2v-CD58 interaction affects CD2v-mediated NF-kB-p65 nuclear translocation and IFN- $\beta$ induction. (A) siRNA knock down of CD58. PK15 cells were transfected with CD58 siRNA or siRNA universal negative control, total RNA was extracted at $24 \mathrm{~h} \mathrm{pt}$, cDNA prepared and CD58 transcription assessed by RT-PCR. Results are mean of five independent experiments

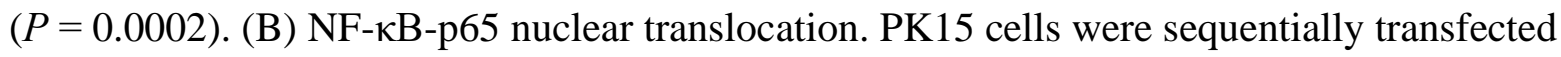
with CD58 siRNA or siRNA universal negative control and pCD2v-HA or pEmpty-HA, fixed at $3 \mathrm{~h}$ pt, and processed for detection of NF- $\mathrm{kB}-\mathrm{p} 65$ by immunofluorescence. Cells were counted from 15 random fields/slide (approximately 100 cells/slide) and results are shown as percentage of CD2v-expressing cells with nuclear NF- $\kappa \mathrm{B}-\mathrm{p} 65$. Results are mean of three independent experiments $(P=0.0035)$. (C) Percentage of CD2v-expressing cells with strong nuclear NF- $\kappa \mathrm{B}-$ p65 translocation $(P=0.0015)$. (D) Representative images of NF- $\mathrm{kB}-\mathrm{p} 65$ nuclear translocation under conditions outlined in A. Green, CD2v; Red, NF-кB-p65; Blue, DAPI. Arrows indicate nuclear NF- $\kappa$ B-p65. (E) IFN- $\beta$ induction. PK15 cells were sequentially transfected with CD58 siRNA or siRNA universal negative control, and pCD2v-HA or pEmpty-HA. Total RNA was extracted at $6 \mathrm{~h}$ pt, cDNA prepared and transcription of IFN- $\beta$ assessed by RT-PCR. Fold

943 changes are relative to Empty-HA and data are mean mRNA levels from eight independent experiments $(P=0.025)$. ( ${ }^{*}, P<0.05$ and $\left.* *, P<0.01\right)$. 
$\mathbf{A}$

B
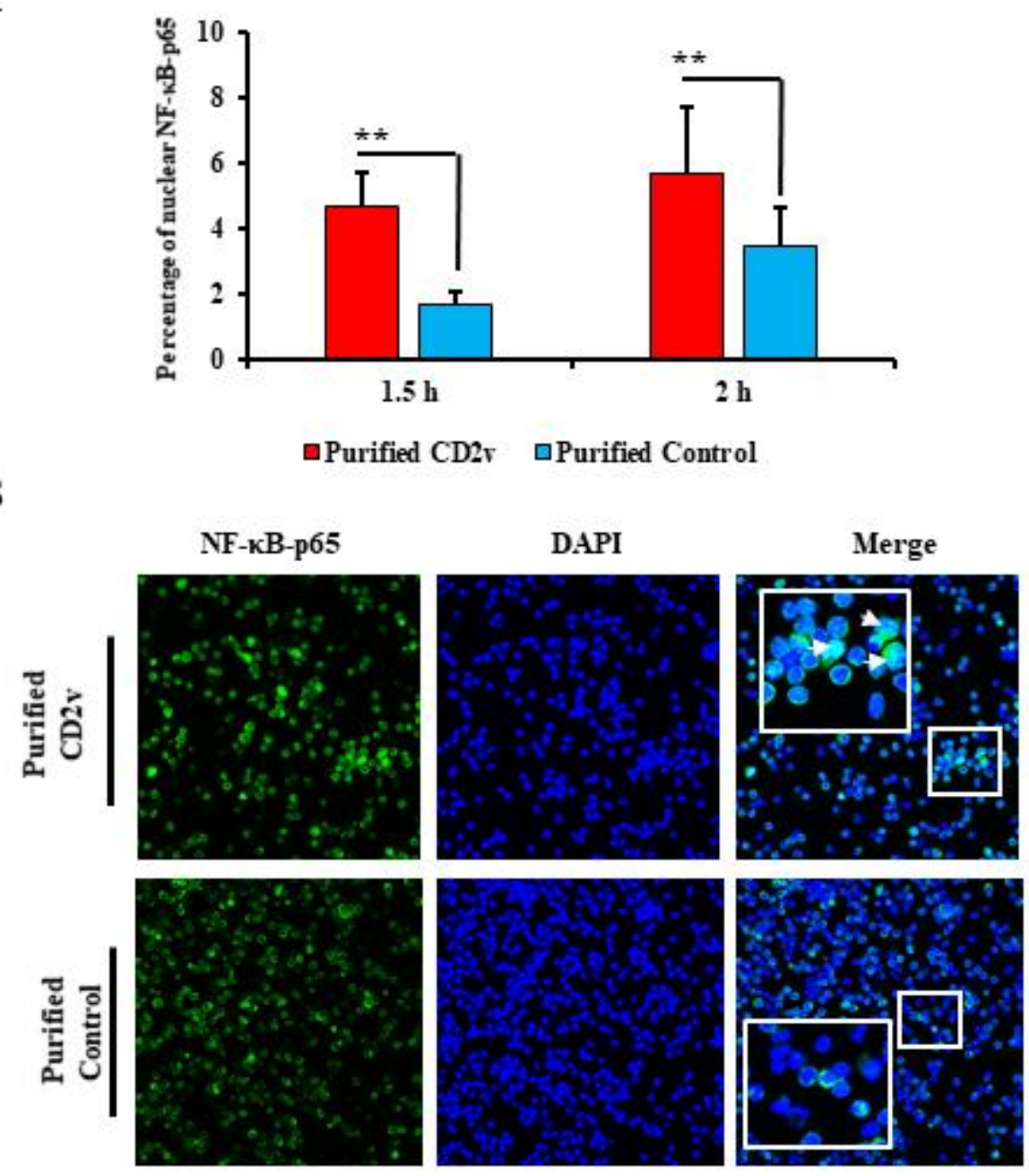

C

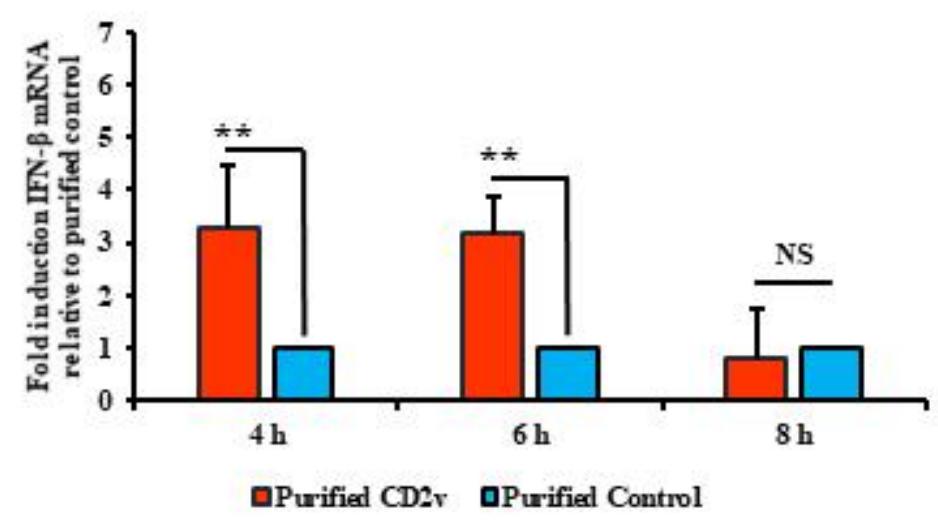


951 FIG 10. Purified CD2v induces NF-kB-p65 nuclear translocation and IFN- $\beta$ transcription

952 in swine PBMCs. Purified CD2v, purified control, and swine PBMCs were obtained as indicated

953 in materials and methods. (A) Swine PBMCs were treated with purified CD2v or purified

954 control, fixed at $1.5 \mathrm{~h}$ and $2 \mathrm{~h}$ post treatment, sequentially incubated with anti-NF- $\mathrm{BB}-\mathrm{p} 65$

955 primary antibody and Alexa fluor 488-labeled secondary antibody, stained with DAPI,

956 cytospined, and examined by confocal microscopy. Cells were counted from 15 random

957 fields/slide (approximately 2000 cells/slide) and results are shown as percentage of cells with

958 nuclear NF- $\mathrm{BB}-\mathrm{p} 65$. Results are mean of four independent experiments $(1.5 \mathrm{~h}, P=0.01 ; 2 \mathrm{~h}, P=$

959 0.012). (B) Representative confocal images of NF- $\mathrm{BB}-\mathrm{p} 65$ nuclear translocation under conditions

960 outlined in A. Green, NF-кB-p65; Blue, DAPI. Insets show magnified areas of the field. Arrows

961 indicate nuclear NF-kB-p65. (C) IFN- $\beta$ induction. Total RNA was harvested at $4 \mathrm{~h}, 6 \mathrm{~h}$ and $8 \mathrm{~h}$

962 post treatment and IFN- $\beta$ transcription was assessed by RT-PCR. Fold changes are relative to

963 purified control and data are mean mRNA levels of seven independent experiments $(4 \mathrm{~h}, P=$

$964 \quad 0.016 ; 6 \mathrm{~h}, P=0.002)$. (*, $P<0.05$ and **, $P<0.01$ ). 
A

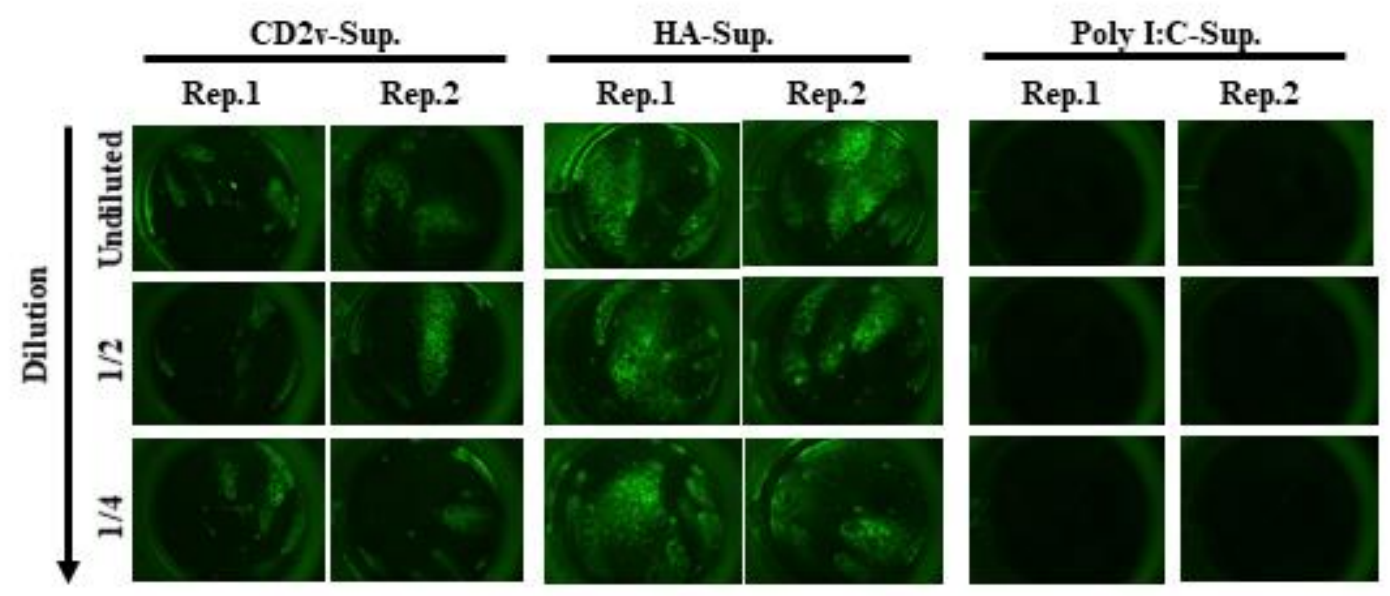

B

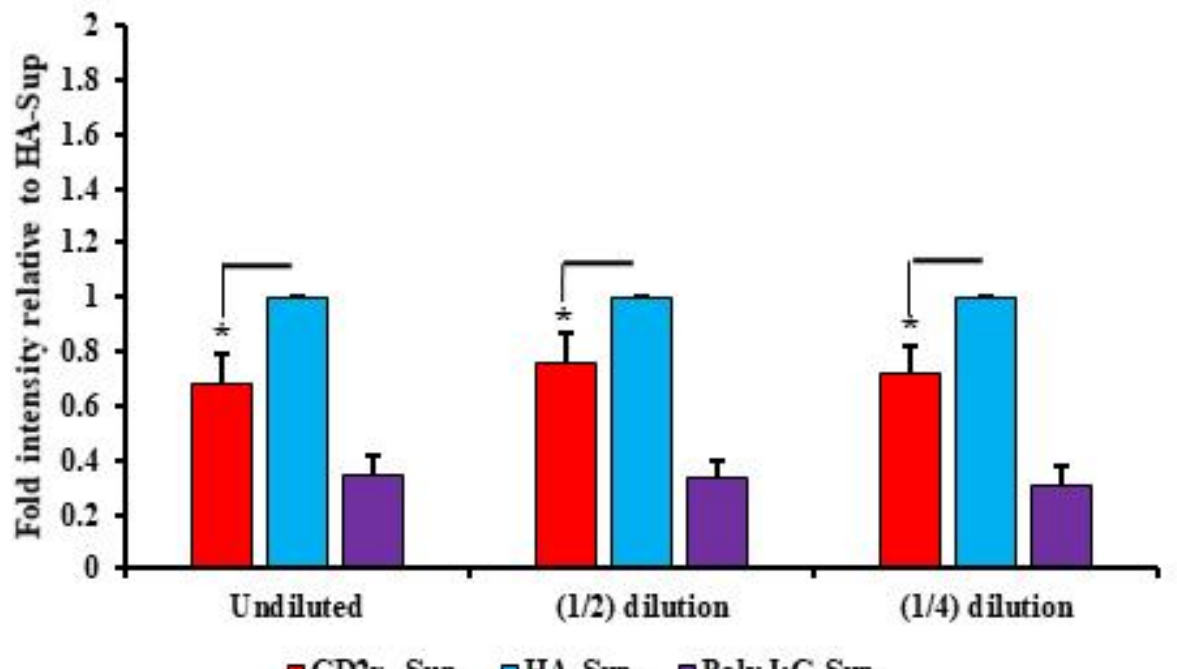

$\square C D 2 r-$ Sup. $\square$ HA-Sup. $\quad$ Poly I:C-Sup. 
971 FIG 11. Antiviral activity of supernatants from CD2v -treated swine PBMCs. Swine PBMCs 972 were treated with purified CD2v protein or purified control, and supernatants collected $24 \mathrm{~h}$ post 973 treatment. Supernatant collected from PK15 transfected with Poly I:C (positive control). PK15

974 grown in 96 well plates were treated with different dilutions of PBMC supernatants for $24 \mathrm{~h}$ and 975 subsequently infected with $\mathrm{VSV}^{\mathrm{GFP}}$ (50 PFU/well) for $16 \mathrm{~h}$. (A) Representative fluorescence 976 images of PK15 fixed at $16 \mathrm{~h}_{\text {post } \mathrm{VSV}^{\mathrm{GFP}} \text { infection. Green, VSV }}{ }^{\mathrm{GFP}}$. Rep., denotes technical 977 replicates. (B) Intensity (mean gray value) measured by ImageJ. Fold changes are relative to 978 purified control and data are mean of four independent experiments. $P$-values relative to purified 979 control for undiluted, 1:2 diluted and 1:4 diluted supernatants were $0.014,0.033$ and 0.017 , 980 respectively $(*, P<0.05)$. 
A



B

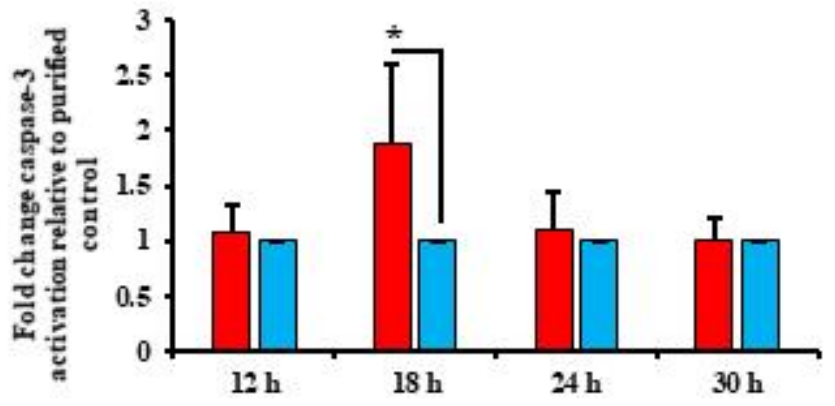

$\square$ Purified CD2v $\quad$ Purified Control

C

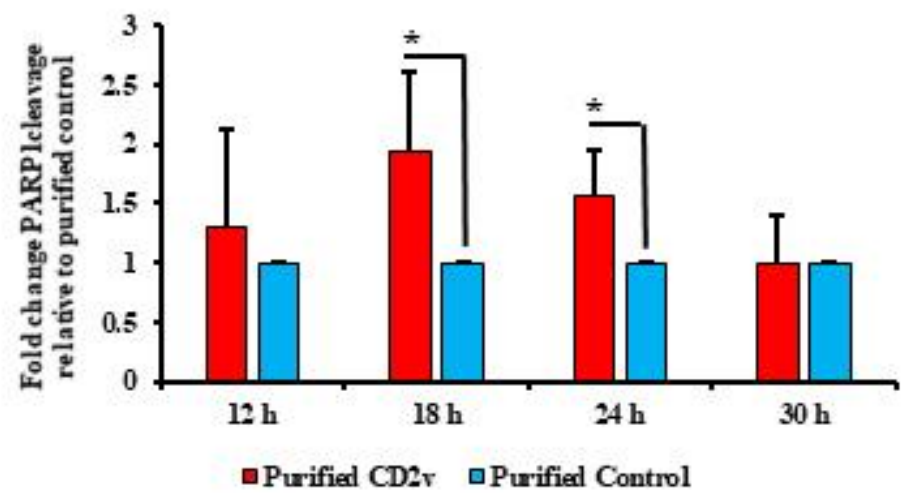


987 FIG 12. Purified CD2v induces apoptosis in swine PBMC (A) Swine PBMC were treated with 988 purified CD2v, purified control, or staurosporine (positive control) and whole cell lysates were 989 obtained at $12 \mathrm{~h}, 18 \mathrm{~h}, 24 \mathrm{~h}$ and $30 \mathrm{~h}$ post treatment, resolved by SDS-PAGE, blotted, and probed 990 with antibodies against Caspase-3, PARP1 and GAPDH. (B) Densitometric analysis showing the 991 fold change in caspase-3 activation relative to purified control treatment, the caspase-3 results 992 are mean values of six independent experiments $(18 \mathrm{~h}, P=0.042)$. (C) Densitometric analysis 993 showing fold changes in PARP1 cleavage relative to purified control treatment. Results are mean 994 values of six independent experiments $(18 \mathrm{~h}, P=0.026 ; 24 \mathrm{~h}, P=0.018)$. $(*, P<0.05)$. 



blots. (A) Purified CD2v or purified control, were resolved by SDS-PAGE, blotted, and probed with anti-CD2v monoclonal antibodies (A4, C4, C3 and F2; top right) or probed with anti-HA antibody (control; top left). Results are representative of three independent experiments. (B) Whole cell extracts were immunoprecipitated with anti-CD2v monoclonal antibodies (upper blot) or anti-HA antibody (control; lower blot), resolved with SDS-PAGE, and probed with antiHA antibody. Results are representative of three independent experiments. ${ }^{*}$ denotes light chain

1008 band. 
A

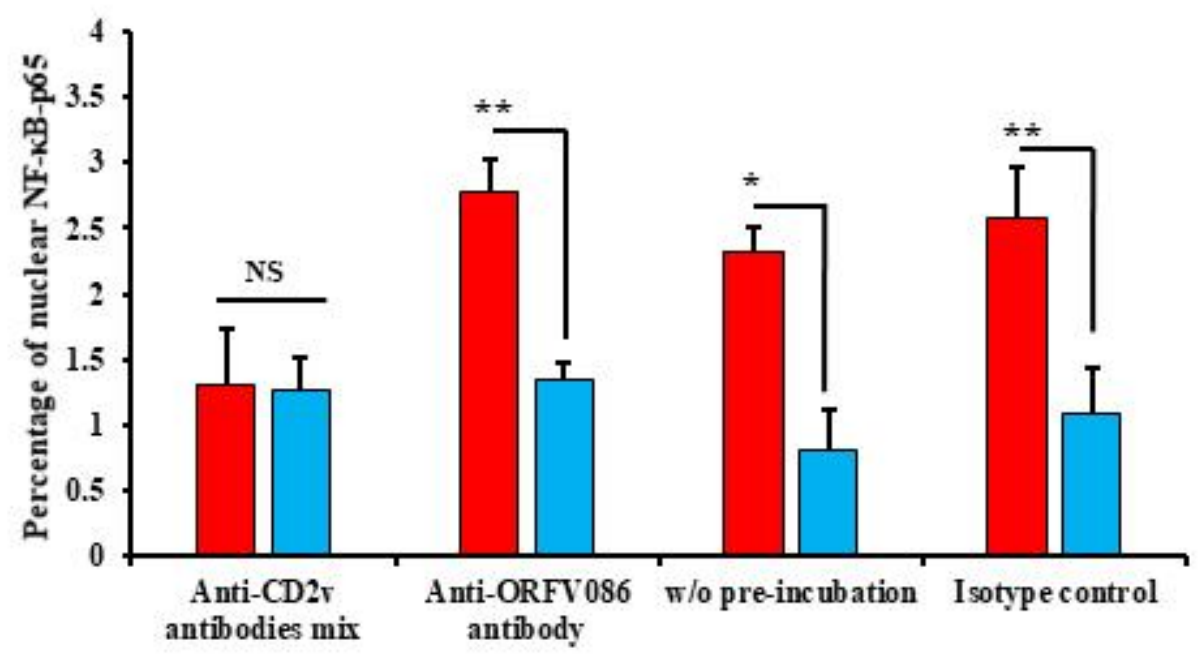

a Purified CD2v $\quad$ aPurified Control

B
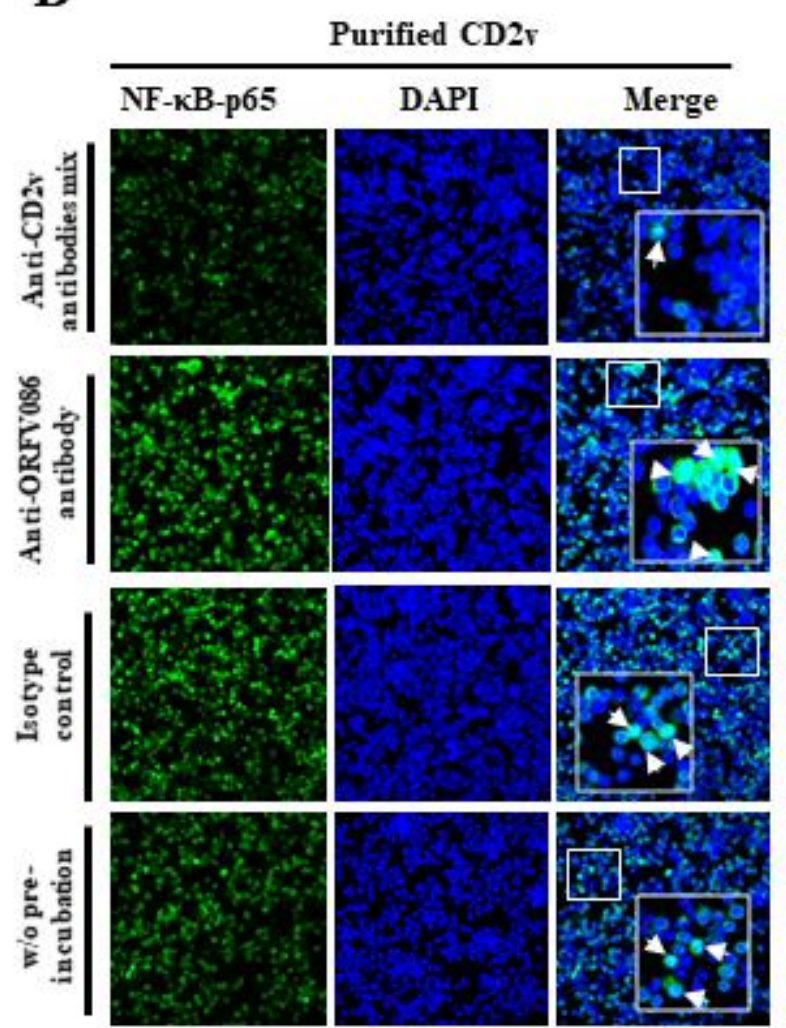
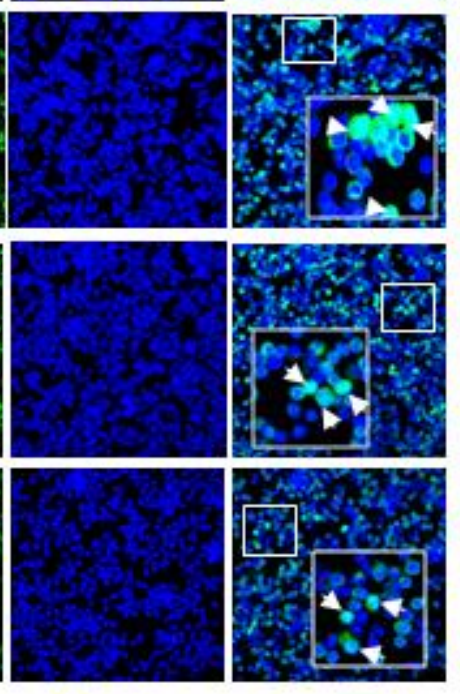
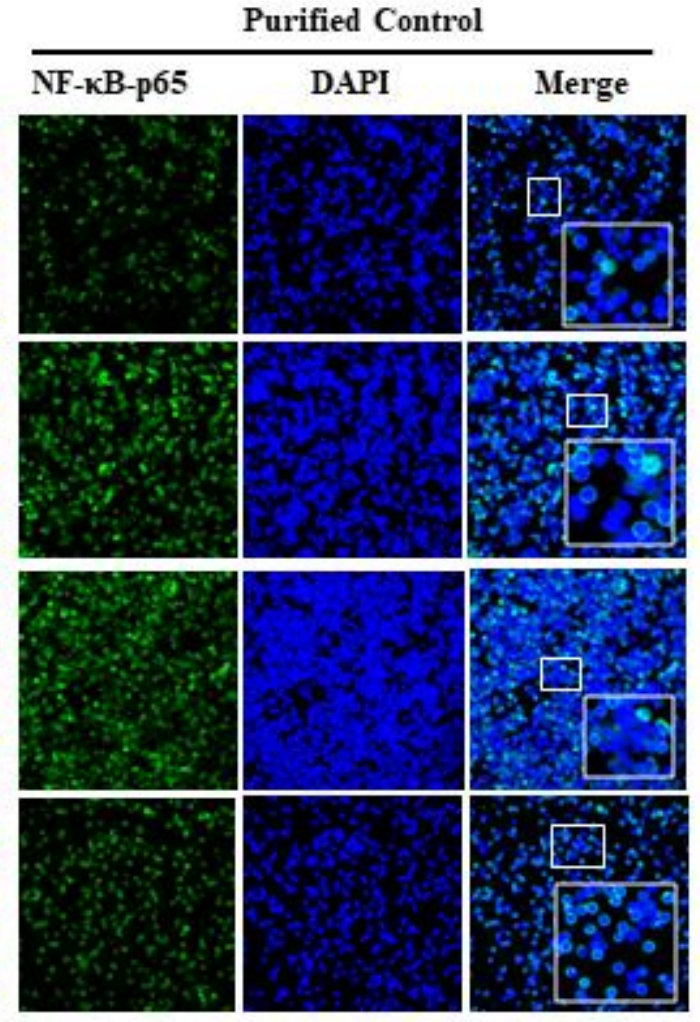


\section{FIG 14. Monoclonal antibodies against ASFV CD2v inhibit CD2v-induced NF-кB}

1016 activation in swine PBMCs. (A) Purified CD2v or purified control pre-incubated with anti-

1017 CD2v monoclonal antibody mix, anti-ORFV086 antibody or isotype control antibody were used 1018 to treat swine PBMCs for $1.5 \mathrm{~h}$, and cells were processed for NF- $\mathrm{BB}-\mathrm{p} 65$ staining by indirect 1019 immunofluorescence as explained in materials and methods. Control cells were treated with $1020 \mathrm{CD} 2 \mathrm{v}$ or purified control that have not been pre-incubated with antibodies. Cells were counted 1021 from 15 random fields/slide (approximately 2500 cells/slide). Results, shown as percentage of 1022 cells with nuclear NF- $\kappa \mathrm{B}-\mathrm{p} 65$, are mean values from three independent experiments (for \% 1023 nuclear NF- $\kappa B-p 65$ for anti-CD2v antibody mix relative to anti-ORFV086, $P=0.012$; without 1024 pre-incubation, $P=0.031$ and for isotype control, $P=0.03$. $\left.{ }^{*}, P<0.05 ; * *, P<0.01\right)(\mathrm{B})$

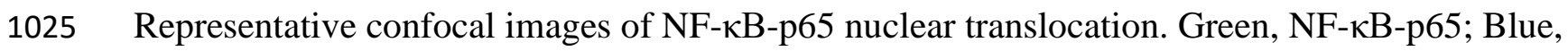
1026 DAPI. Arrows indicate nuclear NF- $\mathrm{BB}-\mathrm{p} 65$. Insets show magnified areas of the field. 


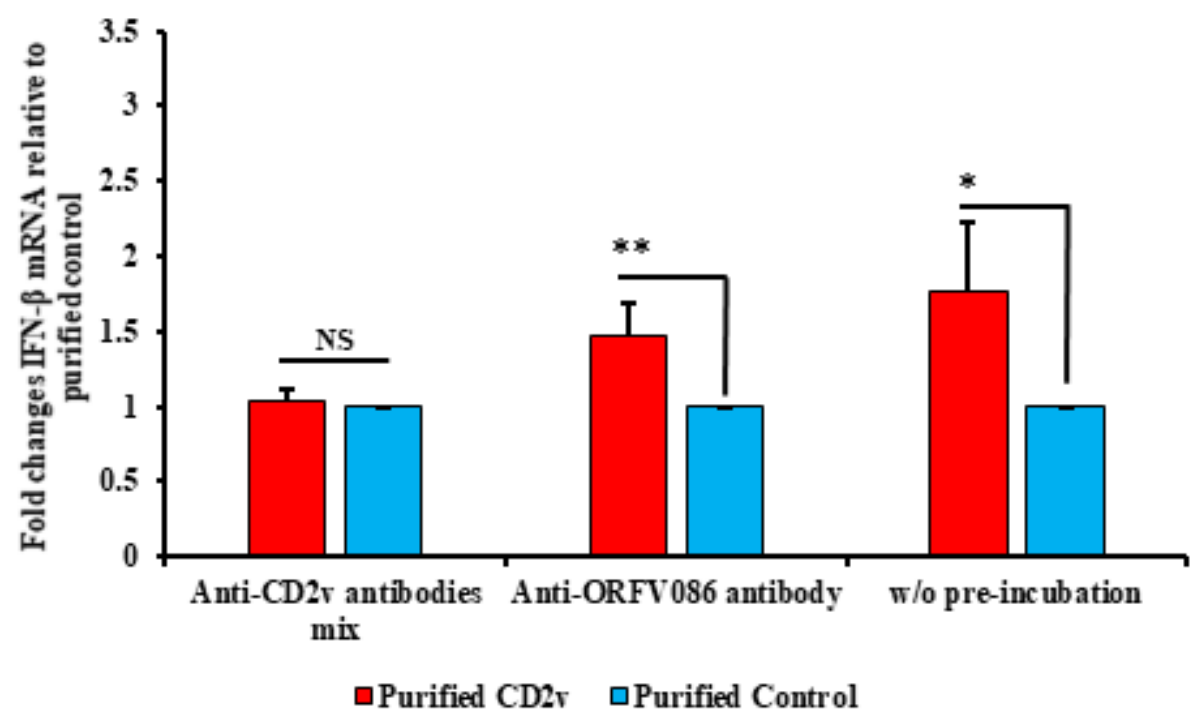

Fig 15. Monoclonal antibodies against ASFV CD2v inhibits CD2v-induced IFN- $\beta$ transcription in swine PBMC cultures. Swine PBMCs were treated with purified CD2v or purified control pre-incubated with anti-CD2v monoclonal antibody mix or anti-ORFV086 antibody, or with the proteins without previous incubation with antibodies. Total RNA was harvested at $6 \mathrm{~h}$ post-treatment, and IFN- $\beta$ transcription was assessed by RT-PCR. Fold changes are relative to purified control and data are mean mRNA levels from five independent experiments. $P$-value for IFN- $\beta$ fold induction for anti-CD2v antibody mix compared to anti- 


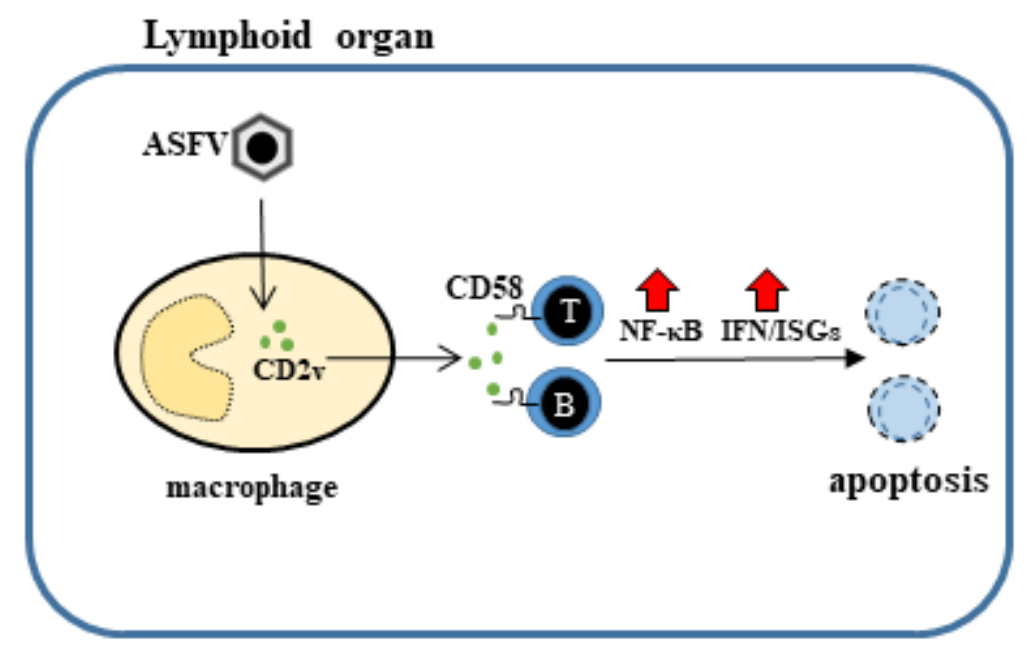

FIG 16. Proposed mechanism of action of ASFV CD2v. CD2v secreted from ASFV-infected

1060 macrophages interacts with by-stander lymphocytes via CD58. This interaction promotes NF- $\kappa \mathrm{B}$

1061 activation and induction of IFN- $\beta$ and ISGs, which lead to lymphocyte apoptosis. 

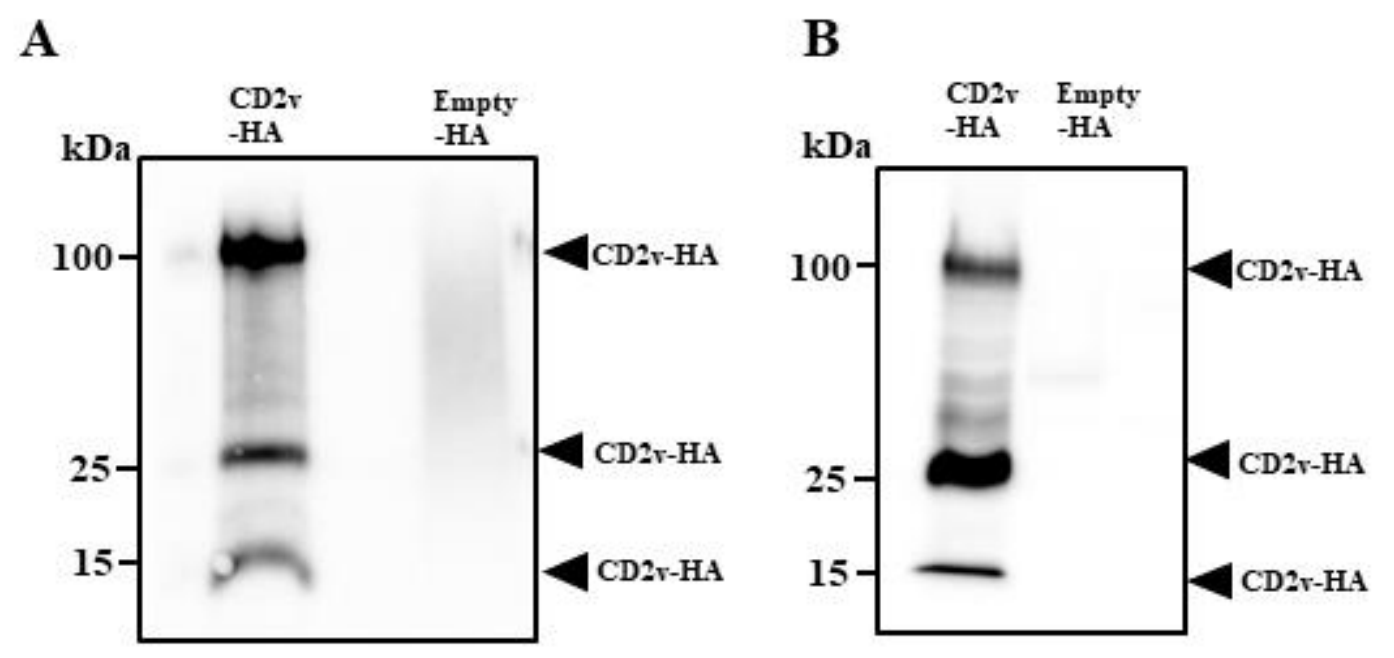

FIG S1. Expression of CD2v in 293T and Vero cells. 293T (A) and Vero cells (B) mock transfected or transfected with plasmid pCD2v-HA were harvested at $24 \mathrm{~h}$ post transfection. Total cell protein extracts were resolved by SDS-PAGE, blotted and incubated with antibodies against HA. Results are representative of two independent experiments. 


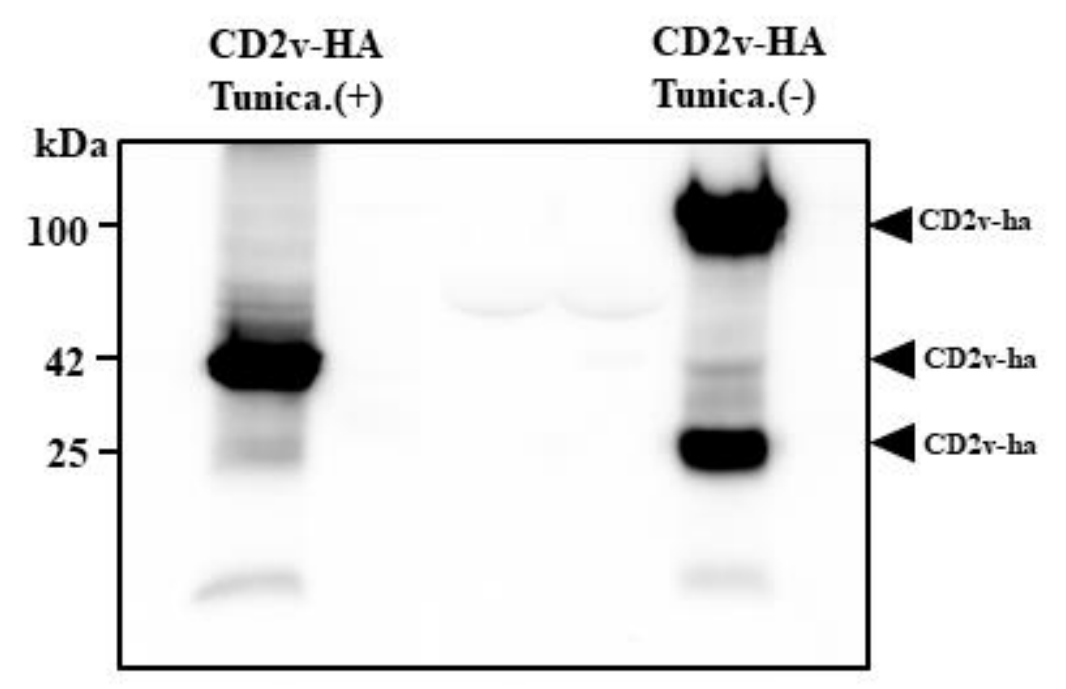

1070 FIG S2. CD2v expression in presence of tunicamycin. Pk15 cells transfected with pCD2v-HA. 1071 Five hours post-transfection, media was replaced with complete growth media containing $1 \mu \mathrm{g} / \mathrm{ml}$ 1072 tunicamycin and incubated for $24 \mathrm{hr}$. Total cell extracts were resolved by SDS-PAGE, blotted 1073 and incubated with antibodies against HA. Results are representative of two independent 1074 experiments.

1075 